\title{
Defect passivation via the incorporation of tetrapropylammonium cation leading to stability enhancement in lead halide perovskite
}

Anurag Krishna $a^{\dagger}$, Mohammad Ali Akhavan Kazemi ${ }^{\dagger}$, Michel Sliwa ${ }^{\ddagger}$, G. N. Manjunatha Reddy ${ }^{\S}$, Laurent Delevoyes, Olivier Lafon ${ }^{\S, \|}$, Alexandre Felten ${ }^{\sharp}$, Mai Trang Do ${ }^{\ddagger}$, Sébastien Gottis ${ }^{\dagger}$, and Frédéric Sauvage ${ }^{\dagger *}$

†Laboratoire de Réactivité et Chimie des Solides (LRCS), CNRS UMR 7314 - Institut de Chimie de Picardie FR 3085, Université de Picardie Jules Verne, 33 rue Saint Leu, FR-80039 Amiens Cedex, France

† Univ. Lille, CNRS, UMR 8516 - LASIR - Laboratoire de Spectrochimie Infrarouge et Raman, F-59000 Lille, France

§ Univ. Lille, CNRS, Centrale Lille, ENSCL, Univ. Artois, UMR 8181-UCCS- Unité de Catalyse et Chimie du Solide, F-59000, Lille, France

\# SIAM Platform, University of Namur, rue de Bruxelles 61, 5000 Namur, Belgium

"Institut Universitaire de France, 1 rue Descartes, F-75231 Paris, France

Keywords: Perovskite solar cells stability, Defect passivation, time-resolved photoluminescence, solid-state NMR spectroscopy

\section{ABSTRACT}

Improving the performances of photovoltaic (PV) devices by suppressing non-radiative energy losses through the passivation of surface defects and enhancing perovskite solar cells stability to the level of standard PV materials represents one critical challenge in the field of perovskite solar cells. We report the beneficial features of introducing a tetrapropylammonium quaternary ammonium $\left(\mathrm{TPA}^{+}\right)$cation that combines two key functionalities, namely surface passivation of $\mathrm{CH}_{3} \mathrm{NH}_{3} \mathrm{PbI}_{3}$ nanocrystals through strong ionic/electrostatic interaction with the surface and bulk passivation via formation of type I heterostructure which acts as a barrier for recombination and reduces water ingress. As a result, non-encapsulated perovskite films with only $2 \mathrm{~mol} \%$ of $\mathrm{TPA}^{+}$ reached power conversion efficiencies over $17 \%$ under spectral irradiance corresponding to air mass (A.M.) $1.5 \mathrm{G}$ conditions. Furthermore, these films retain more than $85 \%$ of the initial 
performance for over 1500 hours under ambient conditions, including a relative humidity of $\sim 55 \pm 5 \%$. The stability of these films is also significantly enhanced at $60{ }^{\circ} \mathrm{C}$ thermal stress or under $85 \%$ humidity storage. Perovskite thin films before and after the $\mathrm{TPA}^{+}$incorporation are characterized by X-ray diffraction, solid-state NMR spectroscopy, optical absorption spectroscopy and SEM imaging.

\section{INTRODUCTION}

Organic-inorganic metal halide $\mathrm{ABX}_{3}$ perovskite solar cells (PSCs) have captivated the scientific community owing to their exceptional opto-electronic properties ${ }^{1-5}$. There has been an unprecedented growth in the field of perovskite-based photovoltaics (PV); for example, the power conversion efficiency (PCE) has augmented from $3.8 \%$ to over $25 \%{ }^{6}$. The extended bandgap tunability of hybrid perovskite halides via a judicious control in the absorber's stoichiometry, in particular within $\mathrm{CH}_{3} \mathrm{NH}_{3} \mathrm{PbI}_{3-\mathrm{x}} \mathrm{X}_{\mathrm{x}}$ solid solution $\left(\mathrm{X}=\mathrm{Br}^{-} \text {or } \mathrm{Cl}^{-}\right)^{5}$, make them highly beneficial as a top cell tandem with crystalline silicon in order to cross the symbolic barrier of $30 \%^{7}$. In the context of these promising technological perspectives, three key issues remain to be addressed: (i) lead content and its potential solubility in real environment, (ii) process transfer from small $\left(<1 \mathrm{~cm}^{2}\right)$ to larger area $\left(>100 \mathrm{~cm}^{2}\right)$ with lower utilization of detrimental solvents, and (iii) to improve the stability of PSCs to reach the standards of siliconbased PV technology ${ }^{8}$.

The archetypal three-dimensional (3D) perovskite-based on methylammonium lead halide composition $\left(\mathrm{MAPb}_{3}\right)$ gathers the best in terms of opto-electronic characteristics but poorest in terms of stability due to its known thermal, moisture and light-induced degradation ${ }^{8-10}$. This limitation stems principally from the intrinsic volatile nature of the methylammonium cation 
which is only in weak coulombic interactions within the inorganic framework ${ }^{11}$. More complex stoichiometries via the use of three different cations in the A-site and two distinct halide anions $\mathrm{Cs}_{\mathrm{x}}\left(\mathrm{FAPbI}_{3}\right)_{\mathrm{y}}\left(\mathrm{MAPbBr}_{3}\right)_{1-\mathrm{x}-\mathrm{y}}$ perovskite has been developed to improve the stability and operational efficiency ${ }^{12}$. For instance, $\mathrm{Cs}_{\mathrm{x}}\left(\mathrm{MA}_{0.17} \mathrm{FA}_{0.83}\right)_{(1-\mathrm{x})} \mathrm{Pb}\left(\mathrm{I}_{0.83} \mathrm{Br}_{0.17}\right)_{3}$ composition enabled PCEs over $20 \%$ while enhancing the thermal stability. However, such complex stoichiometries are metastable leading to phase segregation driven by halide demixing, thus losing gradually the unique opto-electronic properties of the original perovskite ${ }^{13}$.

Depending on the deposition and the crystallization procedure (precursor concentration, annealing temperature and time, vapor treatment, antisolvent, etc.), the resulting film can contain different levels of grain boundaries and punctual defects, such as anionic vacancies or uncoordinated lead owing to their low formation energies. It translates into the formation of shallow traps that require their careful passivation to lower internal non-radiative energy losses and maximize the electron/hole diffusion length. The two kind of defects, extrinsic related to the film morphology and intrinsic related to crystallographic punctual defects, play a pivotal role not only for achieving high power conversion performances but also to reach long-term stability as they can facilitate oxygen and/or moisture ingress, thus accelerating the device degradation ${ }^{14-16}$.

One credible approach to enhance the PSC's stability is the development of lowerdimensional structures derived from the Ruddlesden-Popper (LDRP) structure of composition $\mathrm{A}_{n-1}^{\prime} \mathrm{A}_{2} \mathrm{~B}_{n} \mathrm{X}_{3 n+1}$, where $\mathrm{A}$ is the additional large organic cation (e.g., n-butyl ammonium, phenethylammonium or ethylenediammonium) and $n$ represents the number of inorganic slabs separated by A. The large organic cations can more strongly interact with the inorganic $\left[\mathrm{PbI}_{6}\right]^{4-}$ octahedra framework through hydrogen and ionic bonding, thus enhancing the overall structural robustness ${ }^{17,18}$. However, they have a stronger insulating character across the layers that 
enhances quantum confinement. This leads to a larger bandgap ( $>2 \mathrm{eV}$ ), a higher exciton binding energy $(\sim 300 \mathrm{meV})^{19}$ and anisotropic charge transport, thus lowering solar cell performances with the highest PCE reported so far at ca. $13 \%{ }^{20-23}$.

Combining the high performances of the $3 \mathrm{D}$ perovskite with the stability of the $2 \mathrm{D}$ perovskite constitutes an essential stake in the technological and scientific roadmap of PSCs. Different approaches have been proposed so far, such as coating the 3D perovskite with a more stable 2D perovskite that can be moisture resistant ${ }^{14,24-26}$ or mesostructuring $2 \mathrm{D}$ and $3 \mathrm{D}$ perovskites in the same volume ${ }^{17,27-29}$.

In this work, we introduced the tetrapropylammonium cation $\left(\mathrm{TPA}^{+}\right)$at the A-site along with methylammonium $\left(\mathrm{MA}^{+}\right)$to create a mesoscale engineered absorber. The strategy behind the use of $\mathrm{TPA}^{+}$, which is also a short-chain cationic surfactant, lies in its ability to strongly interact with the surface of the perovskite crystals through strong electrostatic and ionic interactions to stabilize the uncoordinated halide ions and to passivate surface defects ${ }^{14,30}$. As a result of these two functions, which are herein discussed on the basis of X-ray diffraction (XRD), solid-state NMR spectroscopy as well as time- and spatially-resolved UV-visible spectroscopies, films containing $\mathrm{TPA}^{+}(<4 \mathrm{~mol} \%)$ exhibit longer excited-state lifetime and enhanced luminescence homogeneity at mesoscale than films with no TPA ${ }^{+}$. Optimized PV devices based on quaternary ammonium reached PCE over 17\% under air mass (A.M.) $1.5 \mathrm{G}$ conditions while drastically reinforcing the device stability against humidity, temperature and light stress without any means of external encapsulation.

\section{RESULTS AND DISCUSSION}


Tetrapropylammonium iodide (TPAI) was added to the perovskite precursor solution containing MAI and $\mathrm{PbI}_{2}$, in order to create a $\mathrm{MA}^{+}$deficient film including $\mathrm{TPA}^{+}$cations with a molar fraction of either 2 or $4 \mathrm{~mol} \%$. This leads to a mixed-phase perovskite of general formula $\mathrm{TPA}_{x} \mathrm{MA}_{1-\mathrm{x}} \mathrm{PbI}_{3}$ assuming the stoichiometry in solution to be kept in the film. The molar fractions exceeding $4 \mathrm{~mol} \%$ of TPAI leads to morphological issues of the resulting film, which exhibits cracks and voids. To gain insight into the morphology and crystallinity of $\mathrm{MAPbI}_{3}$ (MAPI) thin films before and after the incorporation of TPA ${ }^{+}$cations, XRD measurements were conducted, analyzed and compared. All of these three films, $\mathrm{MAPbI}_{3}, \mathrm{TPA}_{x} \mathrm{MA}_{1-\mathrm{x}} \mathrm{PbI}_{3} 2 \%$ and $\mathrm{TPA}_{x} \mathrm{MA}_{1-\mathrm{x}} \mathrm{PbI}_{3} 4 \%$ showed a strong preferential orientation along the (110) plane, indicating that the long (001) axis of the tetragonal unit cell is mainly perpendicular to the substrate (Figure 1a). This preferential growth, corresponding to the dense lead and iodide facets of the crystal structure, is typically encountered in high-quality perovskite films, thus providing the best performances in terms of charge collection, PCE and photoluminescence quantum yield ${ }^{31-33}$. For the reference MAPI, an additional diffraction peak at $2 \theta=12.7^{\circ}$ is observed. This latter is assigned to the (001) plane of the hexagonal $\mathrm{PbI}_{2}$ phase, which originates from the 9 mol. \% excess of $\mathrm{PbI}_{2}$ introduced for the film preparation to optimize the PCE of MAPI as demonstrated in the literature ${ }^{34}$. At $2 \%$ and $4 \%$ of $\mathrm{TPA}^{+}$, the intensity of the $\mathrm{PbI}_{2}$ diffraction peak at $12.7^{\circ}$ diminishes which means that TPAI reacts with the excess of $\mathrm{PbI}_{2}$ (Figure 1b). A new diffraction peak appears at a lower angle, $2 \theta=8.1^{\circ}$ (Figure 1c). This new peak, which cannot be indexed into the conventional tetragonal unit cell of $\mathrm{I} 4 / \mathrm{mcm}$ space group, is attributed to an intermediate $\mathrm{TPAPb}_{4} \mathrm{I}_{9}$ phase formed in the presence of excess of $\mathrm{PbI}_{2}$, until this latter is totally consumed (Supporting Information, Figure S1). This confirms the interactions between $\mathrm{TPA}^{+}$cations and lead iodide framework, in particular with iodide anions to which $\mathrm{TPA}^{+}$can bind strongly ${ }^{30}$. By 
comparison, in lead iodide perovskite, the resulting $\mathrm{PbI}_{3}{ }^{-}$frameworks can only accommodate the smallest organic cations such as methylammonium $\left(\mathrm{r}_{\mathrm{eff}}=217 \mathrm{pm}\right)$ and formamidinium $\left(\mathrm{r}_{\mathrm{eff}}=\right.$ $252 \mathrm{pm}$ ) based on the Goldschmidt tolerance factor ${ }^{35}$. Larger moieties at the A-site conducts to the formation of a lower dimensional layered structures ${ }^{36}$. In the case of $\mathrm{TPA}^{+}$, which has a an ionic radius of $450 \mathrm{pm}^{37}$, the Goldschmidt tolerance factor is equal to 1.4 and $\mathrm{TPA}^{+}$cannot be accommodated inside the lattice of the perovskite structure ${ }^{20,21,27}$. However, although this latter cannot be accommodated, $\mathrm{TPA}^{+}$modifies the MAPI lattice. Indeed, a full pattern matching refinement of the MAPI lattice cell parameters has been carried out to evaluate the influence of MAPI lattice cell upon the addition of $\mathrm{TPA}^{+}$. Interestingly, the addition of $\mathrm{TPA}^{+}$provokes a reduction of the cell volume mostly driven by a shrinkage along the (001) direction: $(\mathrm{a}=$ 8.8725(2) $\left.\AA, \mathrm{c}=12.6253(13) \AA ̊ ., \mathrm{V}=993.89(8) \AA^{3}\right)$ and $(\mathrm{a}=8.8720(1) \AA, \mathrm{c}=12.6272(10) \AA, \mathrm{V}=$ 993.93(8) $\AA^{3}$ ) for 2 and 4 mol \% $\mathrm{TPA}^{+}$compared to $(\mathrm{a}=8.8748(1) \AA, \mathrm{c}=12.6591(5) \AA, \mathrm{V}=$ 997.06(4) $\AA^{3}$ ) for pure MAPI (Supporting Information, Table S1). This is an additional evidence supporting that $\mathrm{TPA}^{+}$is not incorporated within the lattice as otherwise it would have yielded to a cell volume expansion ${ }^{29}$. These results suggest that the obtained MAPI film has not exactly same stoichiometry. It is expected to be $\mathrm{MA}^{+}$deficient. Though, a priori, it cannot be ruled out that the $\mathrm{TPA}^{+}$constrains the MAPI lattice leading to the formation of $\mathrm{TPA}^{+}$rich domains and $\mathrm{TPAPb}_{4} \mathrm{I} 9$ domains that are likely to be located at grain boundaries ${ }^{29}$. This second hypothesis is consistent on the one hand with a well-visible crystallite size reduction along (110) plane from $185 \mathrm{~nm}$ for MAPI to 130 and $131 \mathrm{~nm}$ for $(\mathrm{TPA})_{\times}(\mathrm{MA})_{1-\mathrm{PbI}} \mathrm{Pb}_{3} \%$ and (TPA) $)_{\times}(\mathrm{MA})_{1-\mathrm{PbI}} \mathrm{Pb}_{3} 4 \%$, respectively (using Scherrer's equation after subtraction of the instrumental broadening) and on the other hand with the reduction of the particle's size observed by Scanning Electron Microscopy (SEM) (Figure 2). The substitution of $\mathrm{MA}^{+}$by TPA ${ }^{+}$helps to enhance the film's 
quality with a clear reduction of pinholes and less pronounced grain boundaries leading to a more compact, more homogeneous and denser films which result from the surfactant property of $\mathrm{TPA}^{+}$
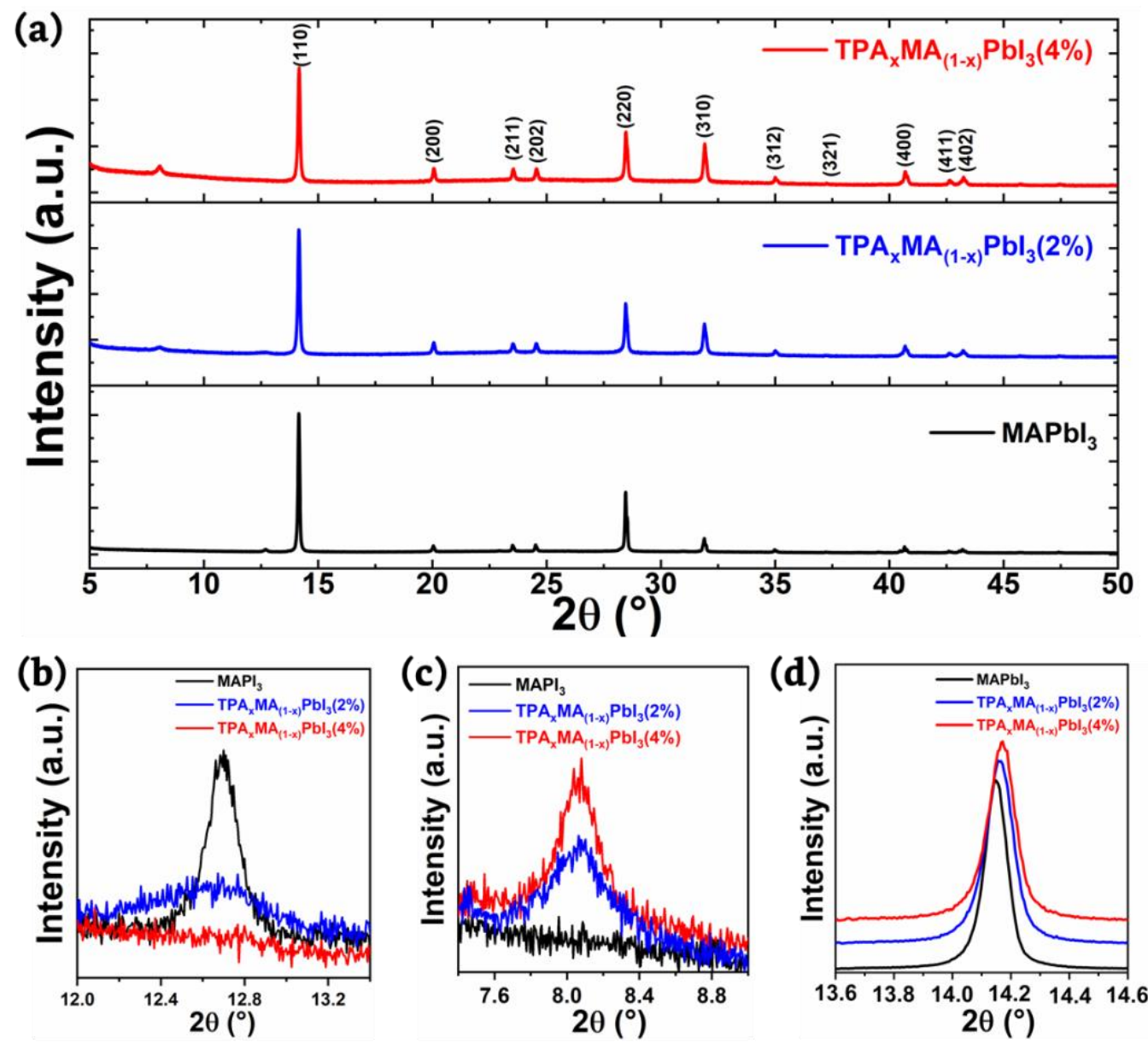

(e)

Phase 1

Phase 2

Phase 1

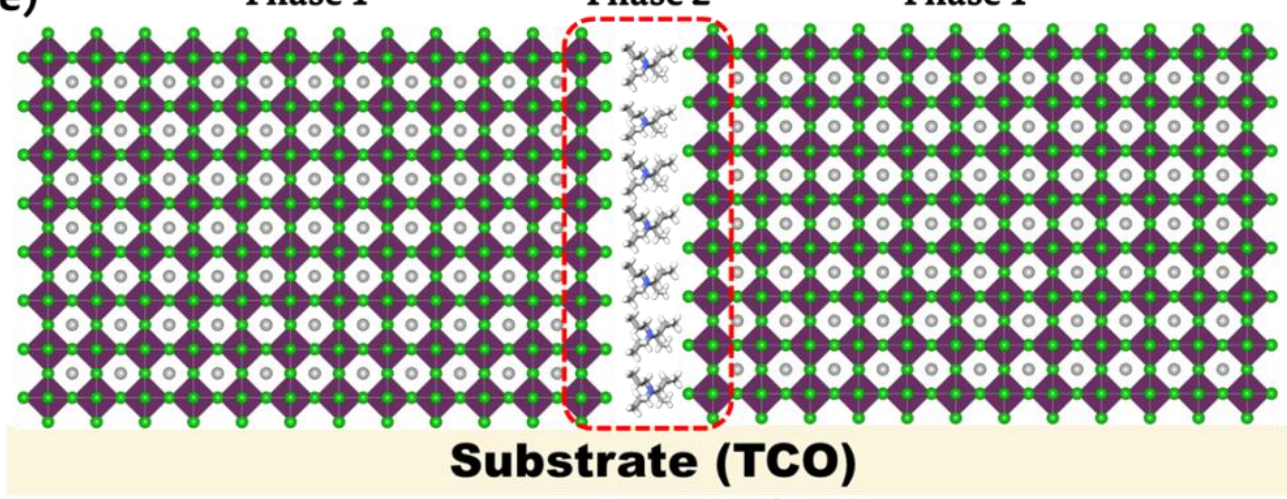

$\odot \mathrm{Pb}^{2+} \odot \mathrm{r}^{-} \odot \mathrm{MA}^{+} \mathrm{KPA}^{+}$ 
Figure 1. (a) Comparison of the XRD patterns of MAPI and TPAxMA ${ }_{1-x} \mathrm{PbI}_{3} 2 \%$ and $4 \%$ films. (b-d) Inset of the evolution of $\mathrm{PbI}_{2}(001)$ diffraction peak at $12.7^{\circ}$, new intermediate phase at $8.1^{\circ}$ and (110) diffraction peak upon addition of TPAI. (e) Schematic showing the selfassembled mixed phase structure.
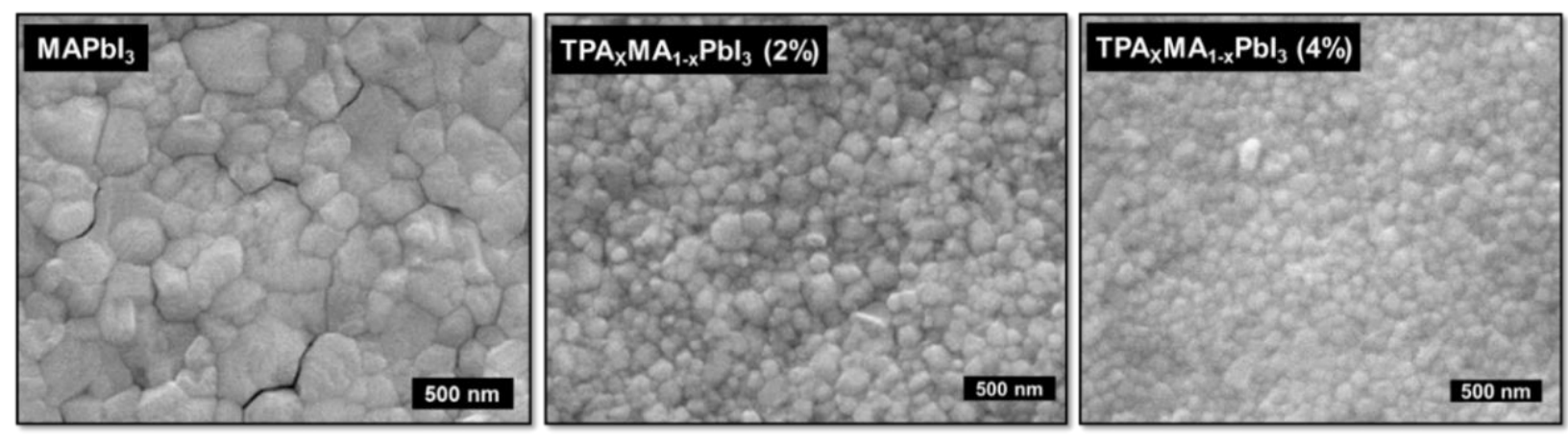

Figure 2. Morphology of Perovskites: Top view scanning electron microscopy images at same magnification of MAPI, TPA $\mathrm{MA}_{1-\mathrm{x}} \mathrm{PbI}_{3} 2 \%$ and $4 \%$ films deposited on a glass substrate.

To further examine the location of $\mathrm{TPA}^{+}$cation in the perovskite materials, we acquired 1D and 2D ${ }^{1} \mathrm{H}$ solid-state NMR spectra of $\mathrm{TPA}_{x} \mathrm{MA}_{1-\mathrm{x}} \mathrm{PbI}_{3} 4 \%$ and its precursor TPAI. The local environments of cations in mixed cations lead halide perovskites has recently been examined using solid-state NMR spectroscopy [Cite: Kubicki, D. J. et al, JACS, 2017, 139, 14173 \& Van Gompel, W. T. M. et al J. Phys. Chem. C 2018, 122, 4171 \& Kubicki, D. J. et al, JACS, 2018, 140, $3345 \&$ Bi, D. et al., Nature Communications 2018, 9 (1), 4482], and especially of protons [Franssen, W. M. J. et al ChemPhysChem 2018, 19, 3107 \& Milić, J. V. et al., Advanced Energy Materials 2019, 0 (0), 1900284 \& Franssen, W. M. J., Kentgens, A. Solid State Nucl. Magn. Reson. 2019, 100, 36 \& Alharbi, E. A. et al.., Nature Communications 2019, 10 (1), 3008 \& Alazani, A. Q. et al JACS DOI: 10.1021/jacs.9b07381]. The 1D ${ }^{1} \mathrm{H}$ MAS NMR spectrum of $\mathrm{TPA}_{x} \mathrm{MA}_{1-\mathrm{x}} \mathrm{PbI}_{3} 4 \%$ is displayed in Figure $3 \mathrm{a}$. This spectrum is dominated by the signals of 
ammonium and methyl groups of $\mathrm{MA}^{+}$cations, resonating at 6.5 and $3.5 \mathrm{ppm}$, respectively. However, three additional weaker signals, at 4.8, 1.3 and $0.9 \mathrm{ppm}$, are assigned to $\mathrm{NCH}_{2}, \mathrm{CH}_{2}$ and $\mathrm{CH}_{3}$ protons of $\mathrm{TPA}^{+}$. The relative integrated intensities of $\mathrm{MA}^{+}$and $\mathrm{TPA}^{+}$signals are consistent with the molar fraction of $4 \mathrm{~mol} \%$ in $\mathrm{TPA}^{+}$. This NMR result indicates that the perovskite film has the same stoichiometry as the solution. Furthermore, the isotropic chemical shifts of $\mathrm{NCH}_{2}(4.8 \mathrm{ppm})$ and $\mathrm{CH}_{2}(1.3 \mathrm{ppm})$ protons of $\mathrm{TPA}^{+}$are deshielded and shielded, respectively, with respect to the ${ }^{1} \mathrm{H}$ signals in the pure of TPAI phase $\left(\mathrm{NCH}_{2}, 2.5-4.5 \mathrm{ppm}\right.$ and $\left.\mathrm{CH}_{2}, 1.8 \mathrm{ppm}\right)$. These different chemical shifts indicate distinct atomic-level environments of $\mathrm{TPA}^{+}$cations in $\mathrm{TPA}_{x} \mathrm{MA}_{1-\mathrm{x}} \mathrm{PbI}_{3} 4 \%$ and pristine TPAI phase, which are consistent with a mixing at microscopic level of $\mathrm{TPA}^{+}$cations and MAPI phase, as shown in Figure 1e. Furthermore, the ${ }^{1} \mathrm{H}$ signals of $\mathrm{TPA}^{+}$cations are narrower for $\mathrm{TPA}_{x} \mathrm{MA}_{1-\mathrm{x}} \mathrm{PbI}_{3} 4 \%$ than the TPAI phase. Such a narrowing is consistent with a close proximity between $\mathrm{TPA}^{+}$cations and lead iodide octahedra, which result in smaller intermolecular ${ }^{1} \mathrm{H}-{ }^{1} \mathrm{H}$ dipolar couplings for the TPA ${ }^{+}$ protons. 

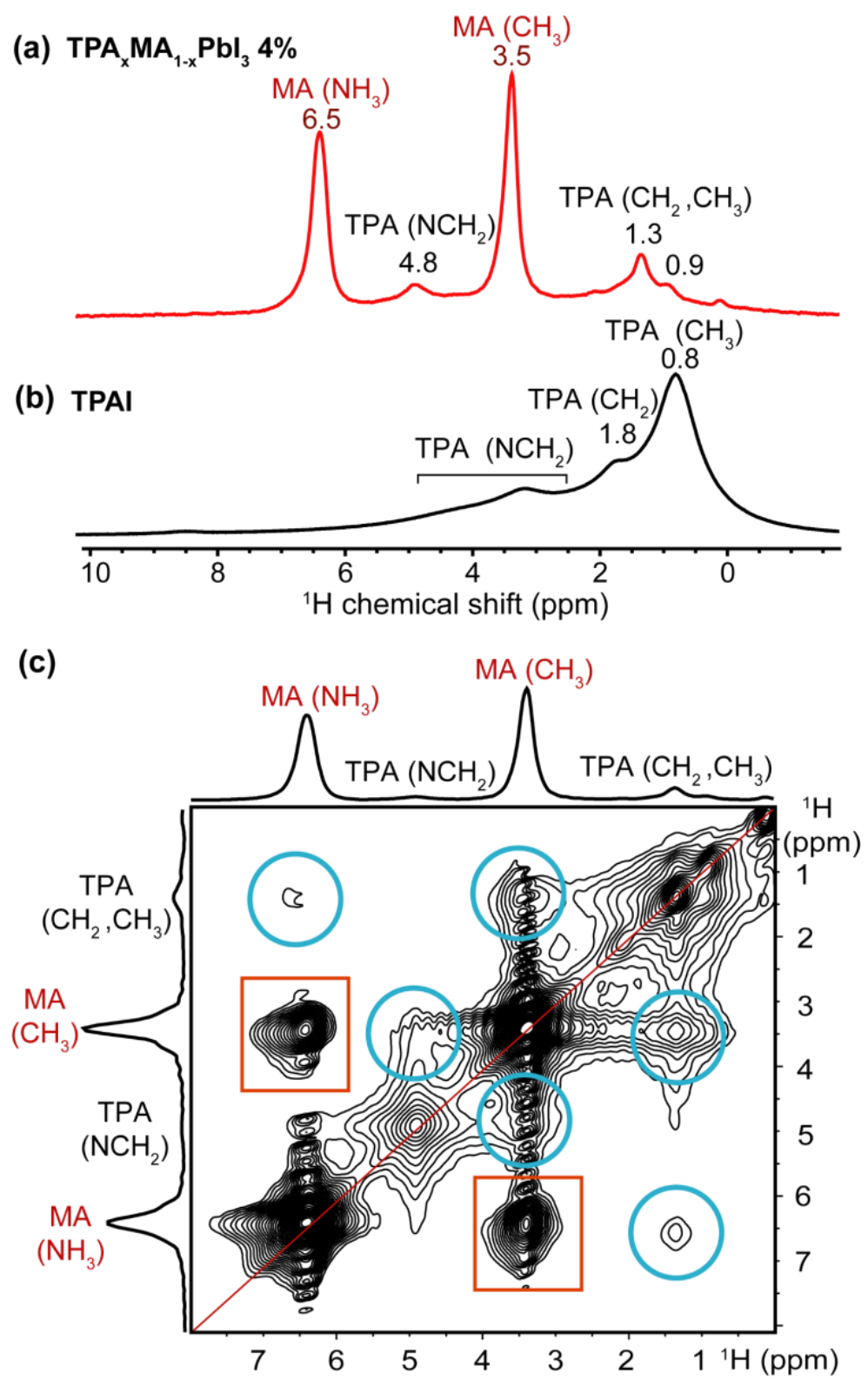

Figure 3. Solid-state 1D ${ }^{1} \mathrm{H}$ MAS NMR spectra of (a) $\mathrm{TPA}_{x} \mathrm{MA}_{1-\mathrm{x}} \mathrm{PbI}_{3} 4 \%$ and (b) TPAI precursor acquired at $18.8 \mathrm{~T}$ with MAS frequencies of 35 and $60 \mathrm{kHz}$ MAS, respectively. (c) 2D ${ }^{1} \mathrm{H}-{ }^{1} \mathrm{H}$ spin-diffusion NMR spectrum of $\mathrm{TPA}_{\mathrm{x}} \mathrm{MA}_{1-\mathrm{x}} \mathrm{PbI}_{3} 4 \%$ acquired at $18.8 \mathrm{~T}$ with a MAS frequency of $35 \mathrm{kHz}$ using $\tau_{\operatorname{mix}}=100 \mathrm{~ms}$. The red rectangles and the cyan circles indicate the cross-peaks corresponding to intra-molecular ${ }^{1} \mathrm{H}-{ }^{1} \mathrm{H}$ dipolar interactions in $\mathrm{MA}^{+}$cations and inter-molecular ones between $\mathrm{MA}^{+}$and $\mathrm{TPA}^{+}$cations, respectively. 
To further corrobate the mixing of $\mathrm{TPA}^{+}$cations and MAPI at microscopic level, we carried out two-dimensional (2D) ${ }^{1} \mathrm{H}-{ }^{1} \mathrm{H}$ spin-diffusion NMR experiments on $\mathrm{TPA}_{\mathrm{x}} \mathrm{MA}_{1-\mathrm{x}} \mathrm{PbI}_{3} 4 \%$ using various mixing times, $\tau_{\operatorname{mix}}$ (see Figure $3 \mathrm{c}$ and Supporting Information, Figure S2) [Cite: Elena, B. et al., Journal of the American Chemical Society 2006, 128 (29), 9555-9560 \& Milić, J. V. et al., Advanced Energy Materials 2019, 0 (0), 1900284 \& Alharbi, E. A. et al.., Nature Communications 2019, 10 (1), 3008 \& Alazani, A. Q. et al JACS DOI: 10.1021/jacs.9b07381]. For $\tau_{\text {mix }}=1 \mathrm{~ms}$, the $2 \mathrm{D}{ }^{1} \mathrm{H}-{ }^{1} \mathrm{H}$ spin-diffusion spectrum only contains diagonal peaks, corresponding to the signals in the 1D ${ }^{1} \mathrm{H}$ NMR spectrum (see Supporting Information, Figure S2a), i.e. no magnetization exchange between the various proton sites occurs during the mixing time. For $\tau_{\operatorname{mix}} \geq 10 \mathrm{~ms}$, cross-peaks are detected, which evidence the exchange of magnetization between different proton sites via ${ }^{1} \mathrm{H}-{ }^{1} \mathrm{H}$ spin diffusion. The intensity of these cross-peaks increases for increasing mixing time. For hybrid perovskites, the cross-peaks can only be observed when the correlated protons are distant by less than a few nanometers. The spectra acquired using $\tau_{\operatorname{mix}} \geq 100 \mathrm{~ms}$ exhibit cross-peaks arising from intra-molecular proximities between ammonium and methyl protons in $\mathrm{MA}^{+}$cations as well as inter-molecular ones between the protons of $\mathrm{MA}^{+}$and $\mathrm{TPA}^{+}$cations. These inter-molecular cross-peaks prove unambiguously that $\mathrm{TPA}^{+}$and $\mathrm{MA}^{+}$are microscopically mixed within the same phase, as shown on Figure 1c. The cross-peaks between TPA ${ }^{+}$protons are not visible even for $\tau_{\text {mix }}=500 \mathrm{~ms}$ because of the low molar fraction of $\mathrm{TPA}^{+}$cations. We also acquired $2 \mathrm{D}{ }^{1} \mathrm{H}$ through-space double-quantum (DQ)single quantum (SQ) homonuclear correlation NMR spectrum of the $\mathrm{TPA}_{x} \mathrm{MA}_{1-\mathrm{x}} \mathrm{PbI}_{3} 4 \%$ (Supporting Information, Figure S3a). Signals in this 2D spectrum are only observed for protons distant by less than $0.5 \mathrm{~nm}$. The signals located on the DQ diagonal, the auto-correlation peaks, reveal proximities between protons with similar isotropic chemical shifts, whereas the off- 
diagonal signals, the correlation peaks, correspond to proximities between sites with distinct isotropic chemical shifts. In the case of $\mathrm{TPA}_{\mathrm{x}} \mathrm{MA}_{1-\mathrm{x}} \mathrm{PbI}_{3} 4 \%$, the ${ }^{1} \mathrm{H}$ through-space DQ-SQ correlation spectrum is dominated by the auto-correlation peaks of $\mathrm{CH}_{3}$ and $\mathrm{NH}_{3}$ groups in $\mathrm{MA}^{+}$ cations as well as the correlation peaks between these two distinct ${ }^{1} \mathrm{H}$ resonances. The spectrum also contains auto-correlation peaks of $\mathrm{TPA}^{+}$cations. Nevertheless, no correlation peak between ${ }^{1} \mathrm{H}$ signals of $\mathrm{MA}^{+}$and $\mathrm{TPA}^{+}$cations can be seen. Hence, $\mathrm{MA}^{+}$and $\mathrm{TPA}^{+}$protons must be distant by more than $0.5 \mathrm{~nm}$ and as shown in Figure $1 \mathrm{c}, \mathrm{TPA}^{+}$cations must interact with the lead iodide octahedra but not with the $\mathrm{MA}^{+}$cations.

The opto-electronic properties of the MAPI and $\mathrm{TPA}_{x} \mathrm{MA}_{1-\mathrm{x}} \mathrm{PbI}_{3}$ perovskite films were investigated by steady-state UV-visible absorption spectroscopy and the position of the valence band determined by Ultraviolet Photon-electron Spectroscopy (UPS) (Figure 4). Regardless of $\mathrm{TPA}^{+}$content in the film, there is no significant change in both the absorption spectra and energy onset (Figure 4a). The Tauc plot, assuming a direct allowed transition in lead halide perovskite, leads to an optical bandgap value of $1.59 \mathrm{eV}$ for all the samples (Figure 4c-e). The bandgap of the second phase $\mathrm{TPAPb}_{4} \mathrm{I}_{9}$ has been determined to be $2.66 \mathrm{eV}$ (Supporting Information, Figure S4). The Urbach energy, $\mathrm{E}_{\mathrm{u}}$, was determined using ${ }^{38}$.

$$
\ln (\alpha)=\ln \left(\alpha_{0}\right)+\frac{\mathrm{hv}}{\mathrm{E}_{\mathrm{u}}}
$$

where $\alpha$ is the absorption coefficient $\left(\mathrm{cm}^{-1}\right), \alpha_{0}$ is a constant and $\mathrm{h} v$ is the photon energy $(\mathrm{eV})$ absorbed in the tail states. Interestingly, one role of $\mathrm{TPA}^{+}$is to alleviate the electronic disorder and surface defects as demonstrated by the lowering in the Urbach energy from $83.6 \mathrm{meV}$ for MAPI to $53.2 \mathrm{meV}$ and $64.1 \mathrm{meV}$ for $\mathrm{TPA}_{x} \mathrm{MA}_{1-\mathrm{x}} \mathrm{PbI}_{3} 2 \%$ and $\mathrm{TPA}_{\mathrm{x}} \mathrm{MA}_{1-\mathrm{x}} \mathrm{PbI}_{3} 4 \%$, respectively 38,39. UPS measurements were carried out to determine the work function and valence band maximum $(\mathrm{VBM})$ position of MAPI and $\mathrm{TPA}_{\mathrm{x}} \mathrm{MA}_{1-\mathrm{x}} \mathrm{PbI}_{3} 2 \%$ from a linear extrapolation of the 
secondary electron cutoff (Figure 4f-h). The work function for MAPI and TPAxMA1-x $\mathrm{PbI}_{3} 2 \%$ was determined to be at $4.23 \mathrm{eV}$ and $4.08 \mathrm{eV}$, respectively. The value of the work function for MAPI is in agreement with what has been previously reported in the literature ${ }^{40}$. The shift of this latter in $\mathrm{TPA}_{x} \mathrm{MA}_{1-\mathrm{x}} \mathrm{PbI}_{3} 2 \%$ stems from an upward movement of the Fermi level in the gap as a result from different punctual defect levels in the film ${ }^{41,42}$. This shift towards ca. $4.10 \mathrm{eV}$ value is also interesting as it tends to suggest a lower level of p-type defects induced by the inclusion of $\mathrm{TPA}^{+}$in good agreement with the studies reported by Duhm et $\mathrm{al}^{41}$. Figure $3 \mathrm{~h}$ schematize the band diagram based on UPS measurements. The VBM position has been determined by the extrapolation of the UPS data plotted on a logarithmic scale $\mathrm{e}^{43,44}$, and is equal to $1.56 \mathrm{eV}$ and 1.58 $\mathrm{eV}$ for MAPI and TPAxMA1-xPbI $32 \%$, respectively (Figure 4g). For TPAxMA1-x $\mathrm{PbI}_{3} 4 \%$, the reproducibility of such measurements was infeasible due to excessive surface charging effects. 
(a)

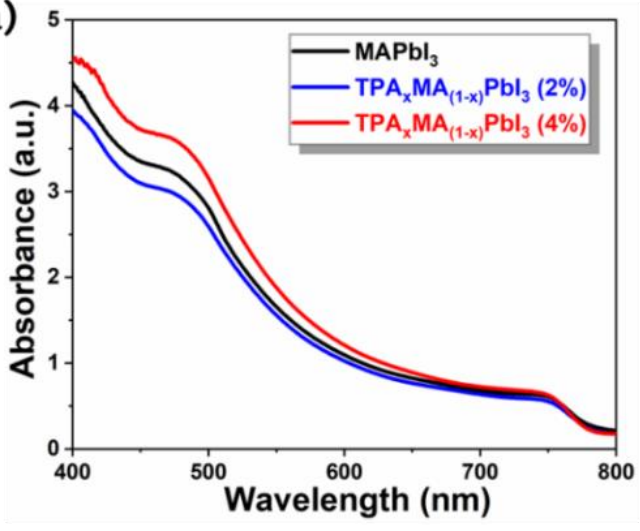

(c)

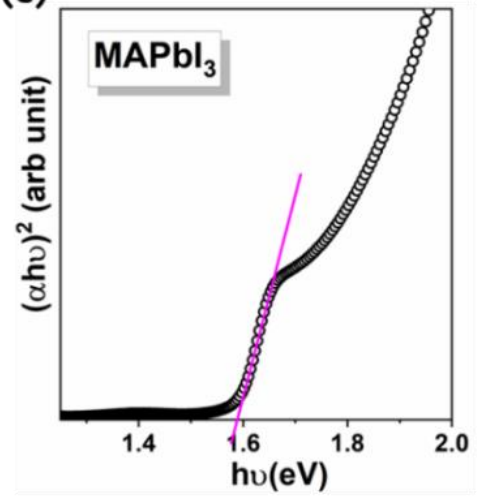

(d)

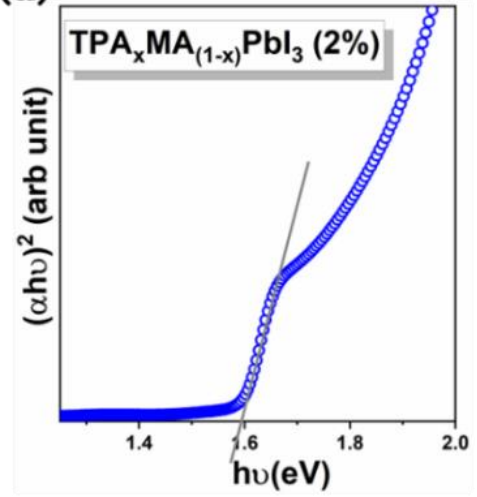

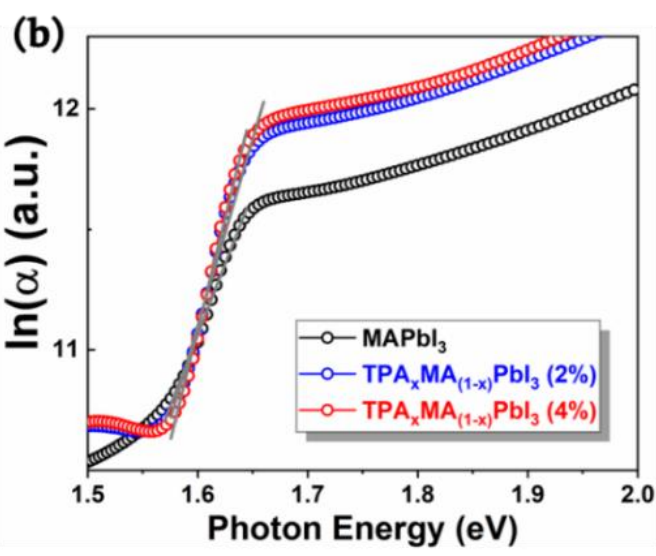

(e)

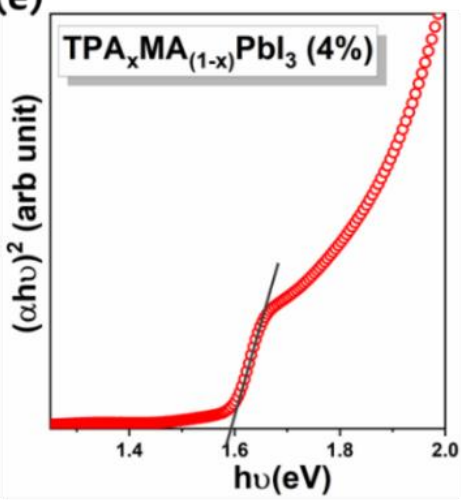

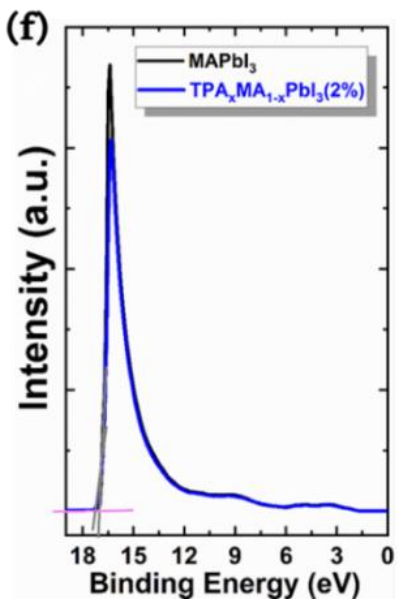

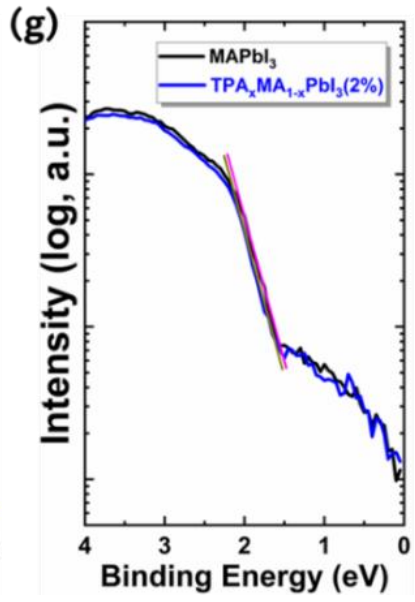

(h)

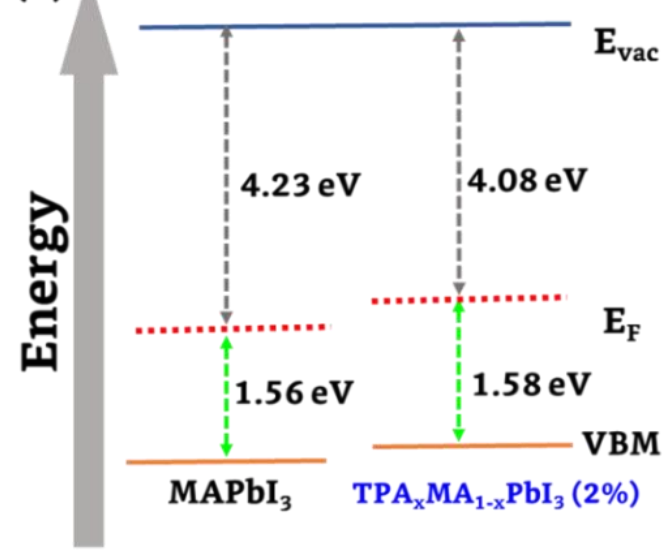

Figure 4. Comparison between MAPI, TPAxMA1-x $\mathrm{PbI}_{3} 2 \%$ and $\mathrm{TPA}_{x} \mathrm{MA}_{1-\mathrm{x}} \mathrm{PbI}_{3} 4 \%$ of (a) steady-state UV-visible absorption spectra; (b) Urbach plot and (c-e) Tauc plot. (f) The secondary electron cutoff of MAPI and $\mathrm{TPA}_{\mathrm{x}} \mathrm{MA}_{1-\mathrm{x}} \mathrm{PbI}_{3} 2 \%$ in UPS measurements; $(\mathrm{g})$ Comparison of UPS measurements in the valence band maximum (VBM) region of MAPI and $\mathrm{TPA}_{\mathrm{x}} \mathrm{MA}_{1-\mathrm{x}} \mathrm{PbI}_{3} 2 \%$ and (h) schematic of the energy levels of the corresponding samples. 
Steady-state photoluminescence (PL) and time-correlated single-photon counting (TCSPC) measurements were carried out to evaluate the modifications in charge carrier dynamics (Figure 5). The steady-state PL yield of TPAxMA1-x $\mathrm{PbI}_{3} 2 \%$ and $\mathrm{TPA}_{x} \mathrm{MA}_{1-\mathrm{x}} \mathrm{PbI}_{3} 4 \%$ films were observed to be four and six times larger than that of MAPI, respectively (Supporting Information, Table S2). This indicates that the addition of $\mathrm{TPA}^{+}$cations leads to successful passivation of non-radiative shallow traps. Interestingly, regardless of the amount of $\mathrm{TPA}^{+}$in the film, we have no evidence of PL fingerprint from the secondary phase in the range of $300-650$ $\mathrm{nm}$ excitation and 350 - $850 \mathrm{~nm}$ emission (Supporting Information, Figure S5). We evaluated the PL lifetime of MAPI, TPA $\mathrm{MA}_{1-\mathrm{x}} \mathrm{PbI}_{3} 2 \%$ and $\mathrm{TPA}_{\mathrm{x}} \mathrm{MA}_{1-\mathrm{x}} \mathrm{PbI}_{3} 4 \%$ films using TCSPC technique (Figure 5b). The PL decay in MAPI perovskite is usually assigned to second order kinetic radiative bimolecular recombination ${ }^{45-47}$. All PL decays were reconvoluted using a biexponential function which is commonly used to describe radiative recombination in perovskites, in particular when $\mathrm{PbI}_{2}$ in excess is introduced in association with an excitation lower than ca. $500 \mathrm{~nm}{ }^{47-49}$. The different values of amplitude, characteristic lifetimes and average lifetime extracted are summarized in Table 1.

Table 1: Summary of lifetime decays determined from the fit to the equations given in the Supporting Information of the TCSPC data displayed in Figure 5b acquired using an excitation wavelength of $475 \mathrm{~nm}\left(2 \mathrm{MHz}\right.$, fluence ca. $\left.100 \mathrm{~nJ} / \mathrm{cm}^{2}\right)$, an emission wavelength of $770 \mathrm{~nm}$ with $10 \mathrm{~nm}$ slit size and a long pass filter of $645 \mathrm{~nm}$.

\begin{tabular}{|c|c|c|c|}
\hline Parameters & MAPbI & TPAx $_{\mathbf{3}} \mathbf{M A}_{\mathbf{1}-\mathbf{x}} \mathbf{P b I}_{\mathbf{3}} \mathbf{( 2 \%} \%$ & TPAx $_{\mathbf{x}} \mathbf{M A}_{\mathbf{1}-\mathbf{x}} \mathbf{P b I}_{\mathbf{3}} \mathbf{( 4 \% )}$ \\
\hline $\mathbf{A}_{\mathbf{1}}$ & 10940 & 5009 & 2016 \\
\hline $\boldsymbol{\alpha}_{\mathbf{1}}(\mathbf{\%})$ & 24.2 & 3.1 & 3.5 \\
\hline $\boldsymbol{\tau}_{\mathbf{1}}(\mathbf{n s})$ & 9.9 & 6.1 & 7.2 \\
\hline $\mathbf{A}_{\mathbf{2}}$ & 6997 & 14641 & 4830 \\
\hline
\end{tabular}




\begin{tabular}{|c|c|c|c|}
\hline $\boldsymbol{\alpha}_{2}(\mathbf{\%})$ & 75.8 & 96.9 & 96.5 \\
\hline $\boldsymbol{\tau}_{\mathbf{2}}(\mathbf{n s})$ & 48.4 & 65.1 & 83.3 \\
\hline$<\boldsymbol{\tau}_{\mathrm{av}}>\mathbf{( n s )}$ & 39.1 & 63.2 & 80.7 \\
\hline
\end{tabular}

The introduction of $\mathrm{TPA}^{+}$in the film leads to a noticeable reduction of the fast contribution from $24 \%$ to ca. $3 \%$. This is attributed in main part to the consumption of $\mathrm{PbI}_{2}$ excess in the film in agreement with recent assignments by Scheblykin et al. ${ }^{49}$. This amplitude reduction of this fast component comes with a longer lifetime of the second contribution from 76 ns to ca. $97 \mathrm{~ns}$, thus signifying that TPA-based films reduces bimolecular radiative recombination dynamics. As a result, we determined the average PL lifetime of the $\mathrm{TPA}_{x} \mathrm{MA}_{1-\mathrm{x}} \mathrm{PbI}_{3} 2 \%$ and $\mathrm{TPA}_{x} \mathrm{MA}_{1-\mathrm{x}} \mathrm{PbI}_{3}$ $4 \%$ to be $63.2 \mathrm{~ns}$ and $80.7 \mathrm{~ns}$, respectively. These values are about two times greater than pure $\mathrm{MAPbI}_{3}$ which is in our case $39.1 \mathrm{~ns}$. This average value is in agreement with the literature for a pure MAPI film excited in the blue region. All these results confirm the interfacial role of TPA ${ }^{+}$ in the suppression of non-radiative monomolecular recombination and prolonging the dynamics of bimolecular radiative recombination, hence conferring improved electronic properties of the perovskite film. We hypothesize that the second phase TPAPb4I9 is formed at the grain boundaries. As aforementioned, the bandgap of MAPI and TPAPb $4 \mathrm{I}_{9}$ is $1.59 \mathrm{eV}$ and $2.66 \mathrm{eV}$, respectively. Due to this narrow and wider bandgap configuration, it forms a type-I heterostructure as schematized in Figure $5 \mathrm{c}^{50}$. In such a type-I heterostructure, when the carriers from MAPI grains are reaching the interface, the electrons-holes $\left(\mathrm{e}^{-} / \mathrm{h}^{+}\right)$carriers are maintained in the bulk of MAPI without suffering from recombination between particles at the grain boundaries owing to interfacial energetic mismatch ${ }^{29,51}$. In other words, the second phase formed upon addition of $\mathrm{TPA}^{+}$acts as a barrier to prevent the recombination. 
Figure 5. Charge carrier dynamics: (a) steady-state $\mathrm{PL}$ measured at $450 \mathrm{~nm}$ excitation wavelength; (b) TCSPC decay of MAPI, TPA $\mathrm{MA}_{1-\mathrm{x}} \mathrm{PbI}_{3} 2 \%$ and $\mathrm{TPA}_{\mathrm{x}} \mathrm{MA}_{1-\mathrm{x}} \mathrm{PbI}_{3} 4 \%$ at $475 \mathrm{~nm}$ excitation (2 MHz, $100 \mathrm{~nJ} / \mathrm{cm}^{2}$ fluence) and at $770 \mathrm{~nm}$ emission with a $645 \mathrm{~nm}$ long pass filter. The films were deposited on a glass substrate and excited from the perovskite side. (c) The coexistence of $\mathrm{TPAPb}_{4} \mathrm{I}_{9}$ and $\mathrm{MAPbI}_{3}$ perovskite in the film shows a type I alignment of the band edge, with the bandgap of 2.66 and $1.59 \mathrm{eV}$, respectively.

Fluorescence lifetime imaging microscopy (FLIM) was used to get further insights into bulk lifetimes, defects and film heterogeneity as previously discussed by deQuilettes et al. ${ }^{47}$. We measured different area in the films cartography representative of fluorescence intensity and lifetimes. As shown in Figure 6, the quantum yield of luminescence is increasing with the 
percentage of TPA ${ }^{+}$in agreement with steady-state and TCSPC experiments. From the average lifetime images (in intensity), we can conclude that the increase of intensity stems from a drastic enhancement in the film's homogeneity associated to the passivation of the surface trap states by $\mathrm{TPA}^{+}$. Indeed, whereas $\mathrm{MAPbI}_{3}$ films are clearly heterogeneous in both the terms of photoluminescence yield and in average lifetimes (Supporting Information, Figure S6), TPA $\mathrm{MA}_{(1-}$ ${ }_{x} \mathrm{PbI}_{3} 4 \%$ becomes very homogenous within the spatial resolution of the FLIM experiments, with an average lifetime about 5 times greater than $\mathrm{MAPbI}_{3}$ in agreement with previous TCSPC study. 
(a)

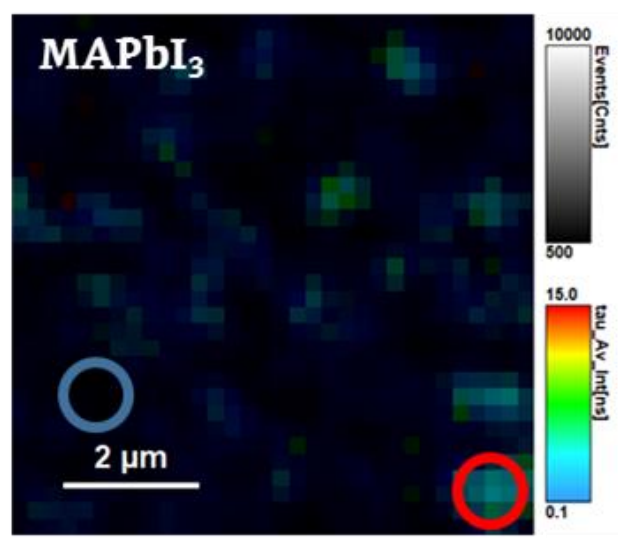

(b)

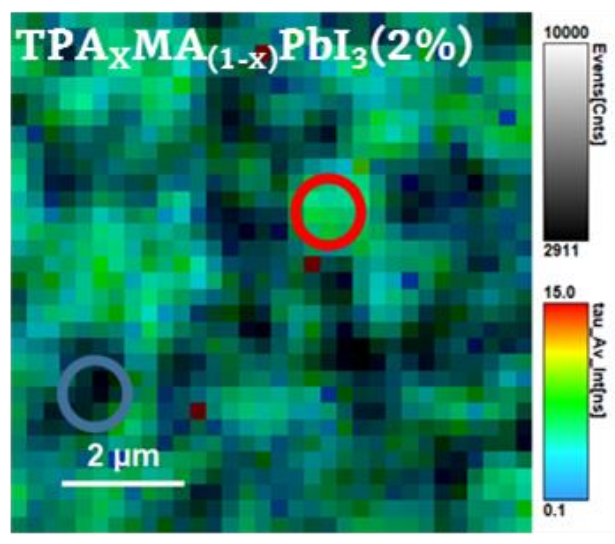

(c)

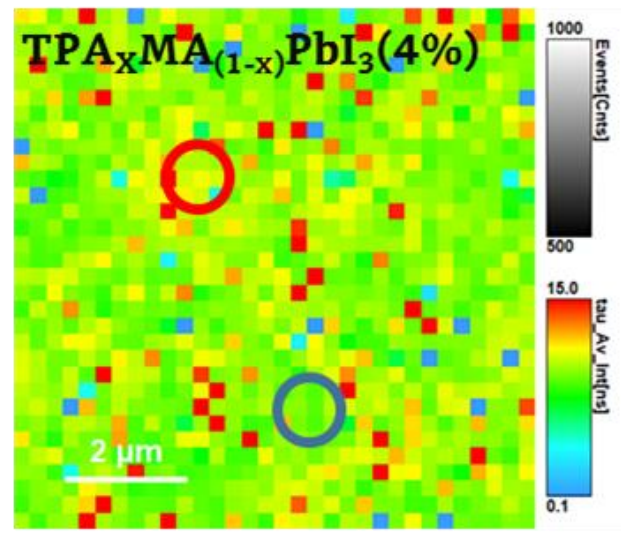

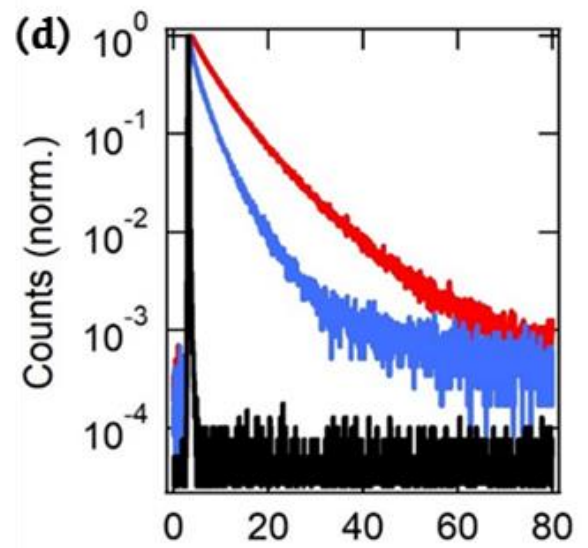
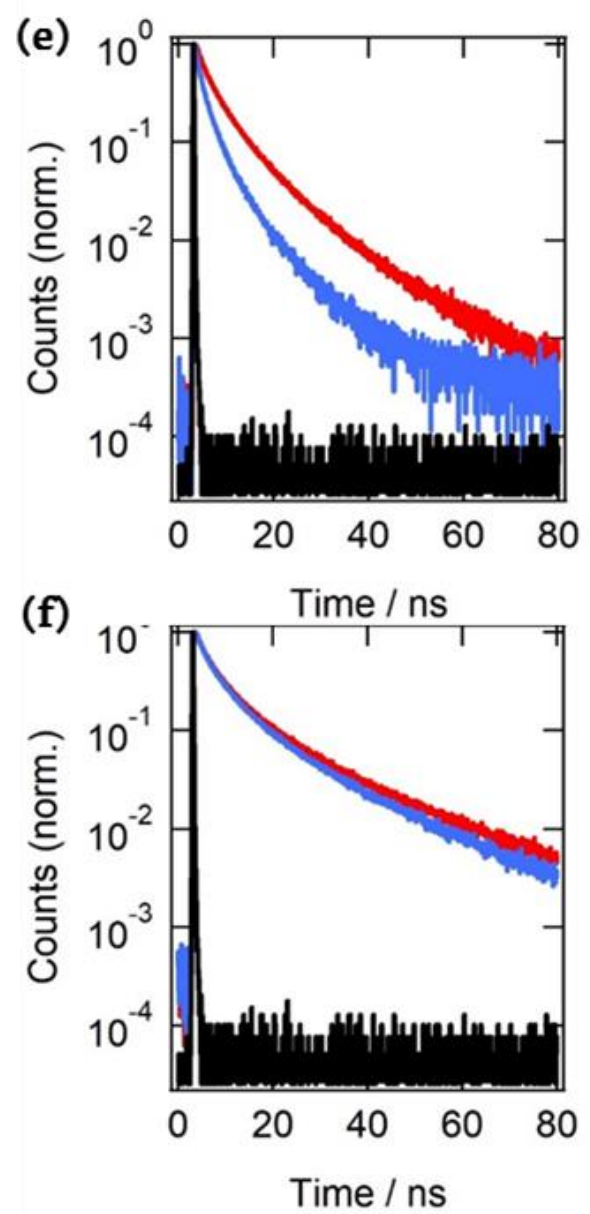

Figure 6. Fluorescence lifetime imaging: Counts and average lifetime for a $8 \mu \mathrm{m}$ by $8 \mu \mathrm{m}$ image (128 by 128 pixels) of (a) $\mathrm{MAPbI}_{3}$, (b) $\mathrm{TPA}_{x} \mathrm{MA}_{(1-\mathrm{x})} \mathrm{PbI}_{3} 2 \%$ and (c) $\mathrm{TPA}_{x} \mathrm{MA}_{(1-\mathrm{x})} \mathrm{PbI}_{3} 4 \%$. Measured decays (until to reach about 104 at the maximum counts) for a pixel in the region with high (red) and low counts (blue) for (d) $\mathrm{MAPbI}_{3}$, (e) $\mathrm{TPA}_{x} \mathrm{MA}_{(1-x)} \mathrm{PbI}_{3}(2 \%)$ and (f) $\mathrm{TPA}_{x} \mathrm{MA}_{(1-}$ ${ }_{x)} \mathrm{PbI}_{3}$ (4\%). $470 \mathrm{~nm}$ laser is used for excitation (100 ps FWHM, $2 \mathrm{MHz}, 5 \mu \mathrm{J} . \mathrm{cm}^{2}$ and photons higher than $650 \mathrm{~nm}$ were detected). 
To gain insight into the beneficial effect of the addition of $\mathrm{TPA}^{+}$cation on the photovoltaic performances and on the device stability, we adopted the following device architecture: fluorine-doped tin oxide (FTO)/blocking (bl) layer- $\mathrm{TiO}_{2} /$ mesoporous (mp)$\mathrm{TiO}_{2} /$ perovskite/spiro-OMeTAD/Au. Figure 7a shows the current density-voltage (J-V) curves of the champion device recorded under A.M. $1.5 \mathrm{G}$ conditions $\left(100 \mathrm{~mW} / \mathrm{cm}^{2}\right)$ based on MAPI, $(\mathrm{TPA})_{\mathrm{x}}(\mathrm{MA})_{1-\mathrm{x}} \mathrm{PbI}_{3} 2 \%$ and $(\mathrm{TPA})_{\mathrm{x}}(\mathrm{MA})_{1-\mathrm{x}} \mathrm{PbI}_{3} 4 \%$ under reverse scan. The corresponding opencircuit photovoltage (Voc), short-circuit current density ( $\mathrm{J}_{\mathrm{SC}}$ ), fill factor $(\mathrm{FF})$ and power conversion efficiency (PCE) are summarized in Table 2. The statistical distribution of the photovoltaic characteristics ( $\mathrm{J}_{\mathrm{SC}}, \mathrm{V}_{\mathrm{OC}}, \mathrm{FF}$, and PCE) from at least 15 devices of each composition is presented in Figure $7 \mathrm{~b}$-e. As a result, MAPI, (TPA) $)_{\mathrm{x}}(\mathrm{MA})_{1-\mathrm{x}} \mathrm{PbI}_{3} 2 \%$ and $(\mathrm{TPA})_{\mathrm{x}}(\mathrm{MA})_{1-\mathrm{x}} \mathrm{PbI} 3$ $4 \%$ showed a maximum PCE of $17.1 \%, 17.2 \%$ and $16.5 \%$, respectively. This suggests that the introduction of $\mathrm{TPA}^{+}$leading to the formation of $\mathrm{TPAPb}_{4} \mathrm{I}_{9}$ intermediate phase does not impede the charge collection at this molar level. The main feature of $\mathrm{TPA}^{+}$for device performance is related to the reduction of internal energy losses. This translates into an enhancement of the cell photo-voltage from $0.972 \mathrm{~V}( \pm 0.019 \mathrm{~V})$ for MAPI to $1.02 \mathrm{~V}( \pm 0.013 \mathrm{~V})$ and $1.04 \mathrm{~V}( \pm 0.014 \mathrm{~V})$ for $(\mathrm{TPA})_{\mathrm{x}}(\mathrm{MA})_{1-\mathrm{x}} \mathrm{PbI}{ }_{3} 2 \%$ and $(\mathrm{TPA})_{\mathrm{x}}(\mathrm{MA})_{1-\mathrm{x}} \mathrm{PbI}_{3} 4 \%$, respectively. This is attributed to the suppression of non-radiative recombination due to the passivation of defects by addition of $\mathrm{TPA}^{+}$ and the longer lifetimes which raise up the quasi-Fermi level in $\mathrm{TiO}_{2}$ nanocrystals ${ }^{52}$. 
(a)

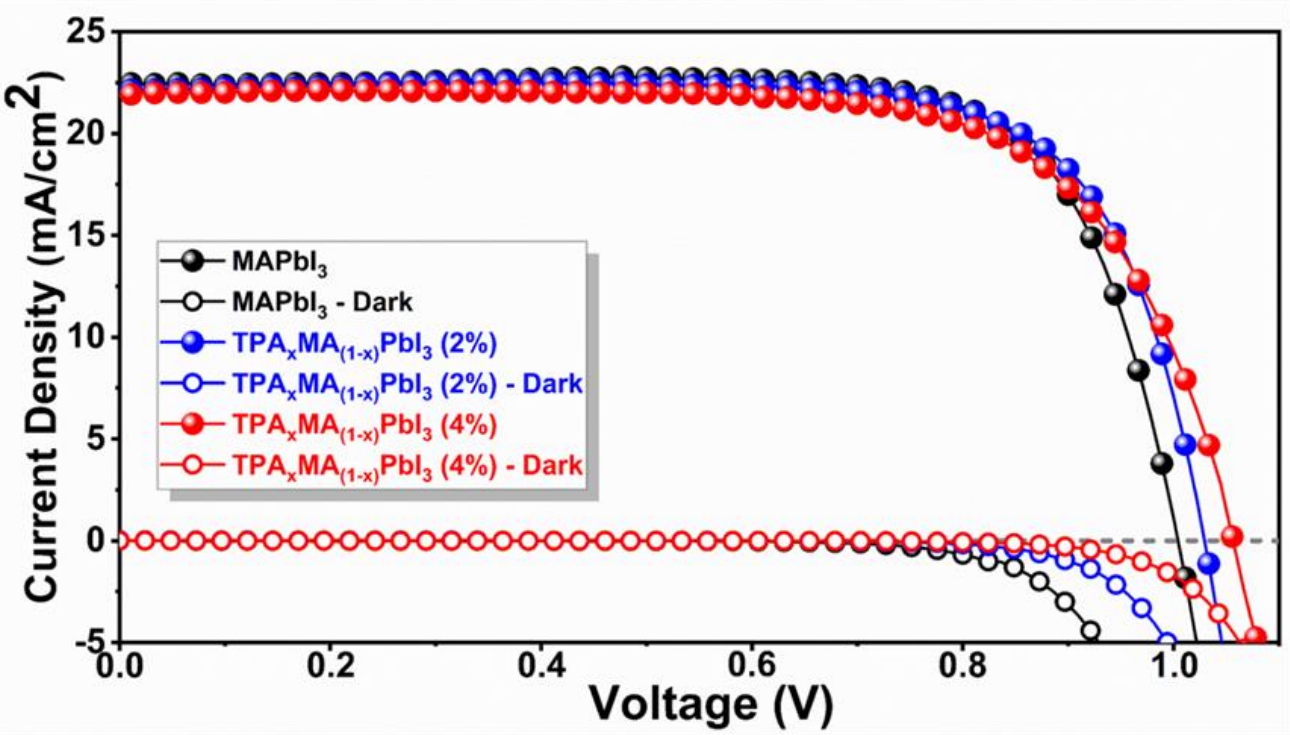

(b)

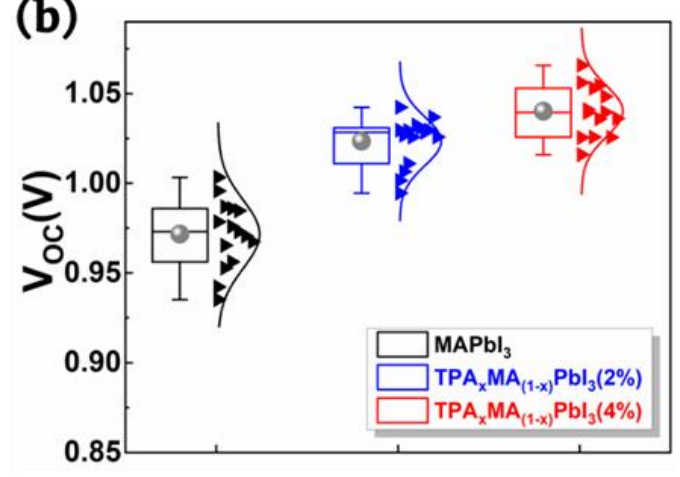

(d)

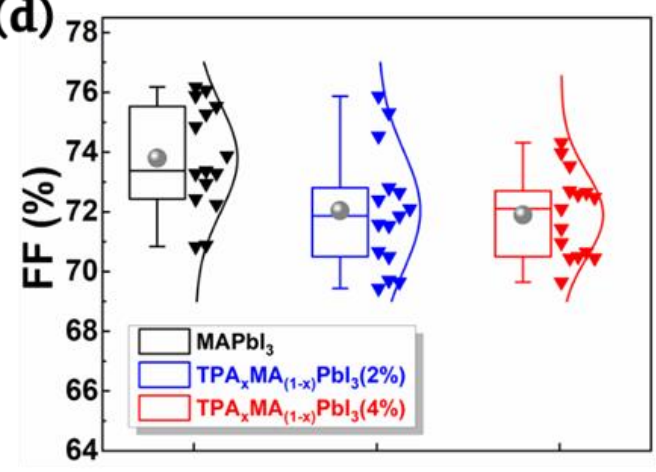

(c)

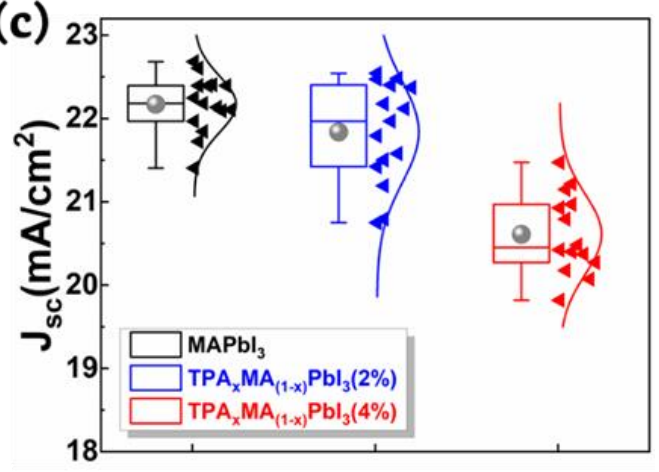

(e)

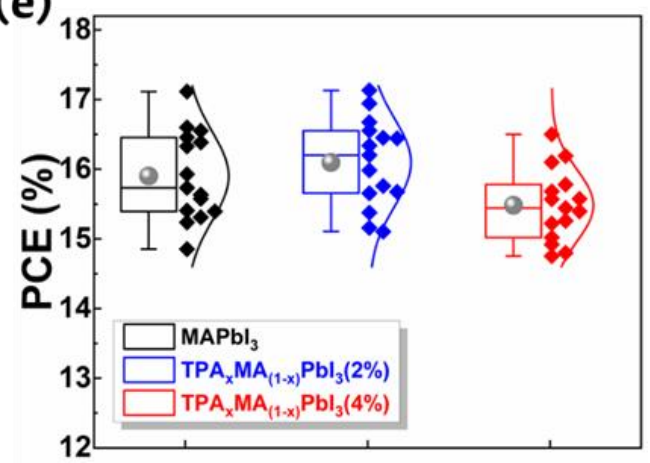

Figure 7. Device performances and statistics: (a) (J-V) curve of the champion cell prepared with MAPI, TPAxMA1-x $\mathrm{PbI}_{3} 2 \%$ and $\mathrm{TPA}_{x} \mathrm{MA}_{1-\mathrm{x}} \mathrm{PbI}_{3} 4 \%$ under $3 \mathrm{~A}$ class Xenon sun simulator at A.M. 1.5G conditions; Statistical data over at least 15 cells for (b) Voc, (c) JSC (d) FF and (e) PCE values for MAPI, TPAxMA1-x $\mathrm{PbI}_{3} 2 \%$ and $\mathrm{TPA}_{x} \mathrm{MA}_{1-x} \mathrm{PbI}_{3} 4 \%$ 
Table 2. Summary of photovoltaic characteristics for devices based on MAPI, TPAxMA $A_{1-x} P_{3} I_{3}$ $2 \%$, and $\mathrm{TPA}_{x} \mathrm{MA}_{1-\mathrm{x}} \mathrm{PbI}_{3} 4 \%$ perovskites. In bracket is the average value including standard deviation (scan rate: $10 \mathrm{mV} / \mathrm{s}$; without any prior light soaking or pre-treatment applied to cell).

\begin{tabular}{|c|c|c|c|c|}
\hline Devices & $\mathbf{V}_{\mathbf{O C}}(\mathbf{V})$ & Jsc (mA/cm $)$ & FF (\%) & PCE (\%) \\
\hline MAPbI & & & & \\
& $(0.972 \pm 0.019)$ & $(22.17 \pm 0.33)$ & $(73.8 \pm 1.78)$ & $(15.9 \pm 0.64)$ \\
\hline $\mathbf{T P A}_{\mathbf{3}} \mathbf{M A}_{\mathbf{1 - \mathbf { x }}} \mathbf{P b I}_{\mathbf{3}} \mathbf{( 2 \% )}$ & 1.03 & 22.1 & 75.3 & 17.2 \\
& $(1.02 \pm 0.013)$ & $(21.84 \pm 0.61)$ & $(72.05 \pm 2)$ & $(16.1 \pm 0.63)$ \\
\hline $\mathbf{T P A}_{\mathbf{X}} \mathbf{M A}_{\mathbf{1 - \mathbf { x }}} \mathbf{P b I}_{\mathbf{3}} \mathbf{( 4 \% )}$ & 1.05 & 21.8 & 72.1 & 16.5 \\
& $(1.04 \pm 0.014)$ & $(20.61 \pm 0.48)$ & $(71.9 \pm 1.43)$ & $(15.5 \pm 0.52)$ \\
\hline
\end{tabular}

The motivation behind $\mathrm{TPA}^{+}$incorporation lies in a possible improvement of the device stability without any means of external encapsulation. Figure 8a compares the device stability under argon atmosphere and ambient conditions $\left(\mathrm{T} \sim 25^{\circ} \mathrm{C}\right)$. The control devices based on MAPI degraded after 400 hours ageing, leading to only $30 \%$ power conversion efficiency retention after 2000 hours ageing. By contrast, the devices based on (TPA $)_{x}(\mathrm{MA})_{1-\mathrm{x}} \mathrm{PbI}_{3} 2 \%$ and $(\mathrm{TPA})_{\mathrm{x}}(\mathrm{MA})_{1-}$ ${ }_{x} \mathrm{PbI}_{3} 4 \%$ retained $90 \%$ and $93 \%$ of initial PCE under same conditions. This remarkable stability improvement is also confirmed under more realistic storage conditions such as moisture (RH $\sim 55 \pm 5 \%$ ), elevated temperature of up to $60{ }^{\circ} \mathrm{C}$ and ambient light exposure (Figure 8b,c). In such conditions, MAPI device showed a monotonous fading of initial performance during the first 400 hours leading to a complete loss of performances after ca. 1300 hours of ageing. By comparison, $(\mathrm{TPA})_{\mathrm{x}}(\mathrm{MA})_{1-\mathrm{x}} \mathrm{PbI}_{3} 2 \%$ and $(\mathrm{TPA})_{\mathrm{x}}(\mathrm{MA})_{1-\mathrm{X}} \mathrm{PbI}_{3} 4 \%$ maintained $80 \%$ PCE retention after ca. 1100 hours and 1900 hours, respectively (Figure 8b). Furthermore, device stability improvement by means of $\mathrm{TPA}^{+}$addition is also confirmed at higher storage temperature, i.e. $60{ }^{\circ} \mathrm{C}$ in argon 
atmosphere (Figure 8c). The argon atmosphere was chosen to avoid degradation from other device components, in particular the hole transporting materials (HTM) which becomes oxygen and moisture sensitive ${ }^{53}$. The MAPI device losses 50\% of its initial PCE after 500 hours ageing. By contrast, $(\mathrm{TPA})_{\times}(\mathrm{MA})_{1-\mathrm{x}} \mathrm{PbI}_{3} 2 \%$ and $(\mathrm{TPA})_{\mathrm{x}}(\mathrm{MA})_{1-\mathrm{x}} \mathrm{PbI}_{3} 4 \%$ can maintain their efficiencies as high as $84 \%$ and $86 \%$ retention under the same conditions. Stability enhancement by the means of substitution by $\mathrm{TPA}^{+}$represents a step forward towards the current state of the art stability in the field. Our work supports that the stability enhancement upon addition of $\mathrm{TPA}^{+}$cation in the film is the result of internal factors such as higher hydrophobicity of the film and external key factors such as denser and fewer defect crystals and grain boundaries since the onset of perovskite degradation is likely proceeding via active defects and grain boundaries ${ }^{54}$. 


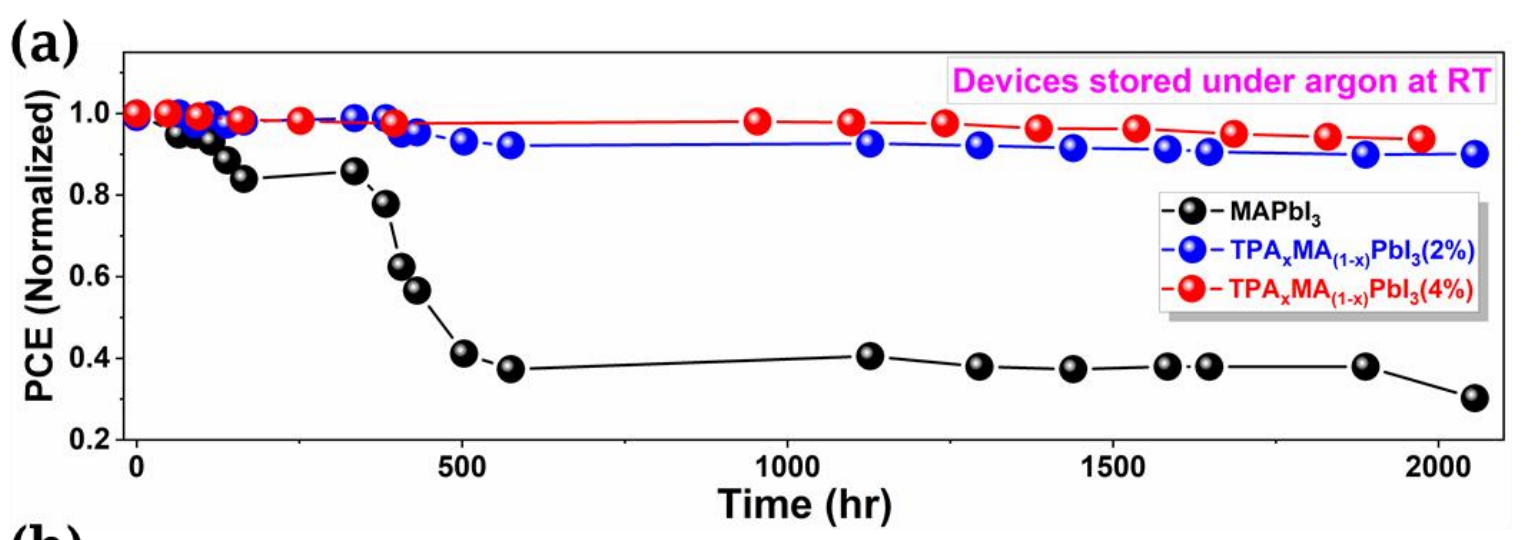

(b)

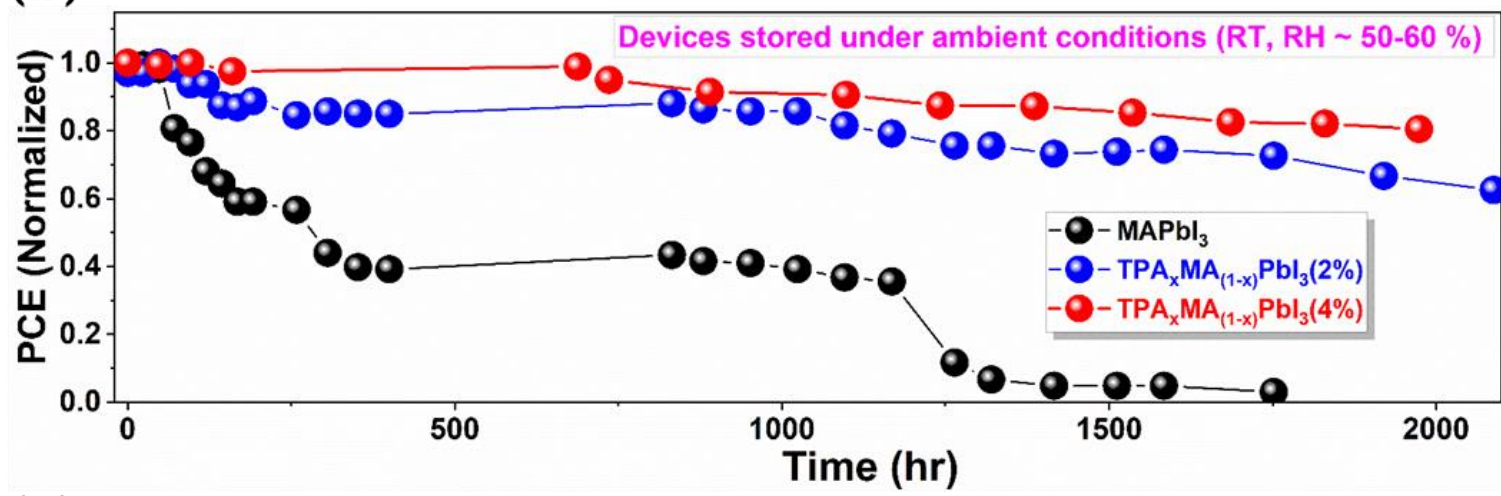

(c)

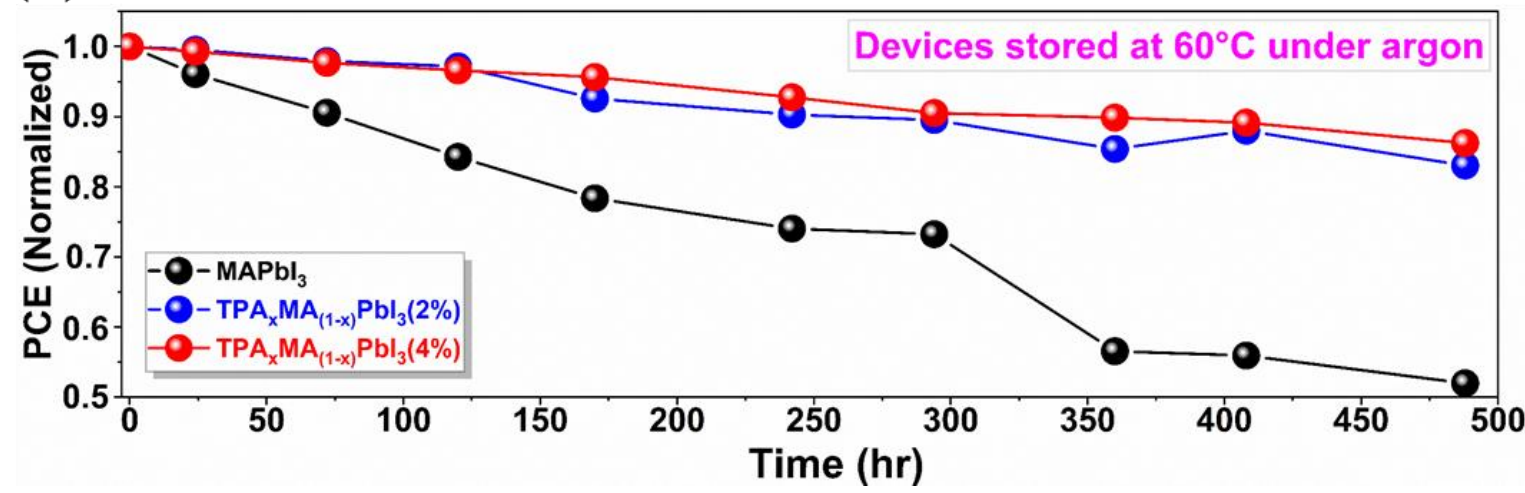

Figure 8. Stability of perovskite solar cells: Stability assessment of non-encapsulated perovskite solar cells based on MAPI, (TPA) $)_{x}(\mathrm{MA})_{1-x} \mathrm{PbI}_{3} 2 \%$ and (TPA) $)_{\mathrm{x}}(\mathrm{MA})_{1-\mathrm{x}} \mathrm{PbI}_{3} 4 \%$ (a) under $25{ }^{\circ} \mathrm{C}$ in argon over 2000 hours. The initial PCE of the devices were 16.6\%, 16.7\%, and 16.2\%, respectively; (b) under $25^{\circ} \mathrm{C}$ over 2000 hours with $\mathrm{RH}$ of $55 \pm 5 \%$ under ambient light. The initial PCE of the devices were $16.3 \%, 16.4 \%$, and $16.0 \%$, respectively; (c) at $60{ }^{\circ} \mathrm{C}$ under argon for 500 hours. The initial PCE of the devices were $16.2 \%, 16.4 \%$, and $16.5 \%$, respectively.

Stability assessment of full devices under stringent humidity conditions remains from the point of view of absorber's side as well as from the hole transporter $(\mathrm{HTM})^{55}$. Indeed, most of 
HTMs required to be doped by means of air-sensitive and highly hygroscopic oxidizing dopants which catalyze the solar cell degradation ${ }^{56}$. Interestingly, we demonstrate in this work that a small inclusion of $\mathrm{TPA}^{+}$in the film allows to drastically reduce the perovskite decomposition into $\mathrm{PbI}_{2}$ under $85 \%$ atmospheric humidity. The comparison of XRD patterns (Figure 9) enabled to identify the changes in long-range structural order in aged MAPI (a), (TPA) $)_{x}(\mathrm{MA})_{1-x} \mathrm{PbI}_{3} 2 \%$ (b) and (TPA) $)_{x}(\mathrm{MA})_{1-\mathrm{x}} \mathrm{PbI}_{3} 4 \%$ (c) perovskite thin films for one-week under $85 \%$ humidity atmosphere. These XRD results and analyses unambiguously demonstrate that the most of the MAPI film decomposed into $\mathrm{PbI}_{2}$ upon exposure to these stringent conditions. By comparison, $(\mathrm{TPA})_{\mathrm{x}}(\mathrm{MA})_{1-\mathrm{x}} \mathrm{PbI}_{3} 2 \%$ and $(\mathrm{TPA})_{\times}(\mathrm{MA})_{1-\mathrm{x}} \mathrm{PbI}_{3} 4 \%$ showed only little formation of $\mathrm{PbI}_{2}$ (Figure 9b,c) which affords to maintain both the UV-visible absorption capability (Supporting Informations, Figures S7-S9) and the perovskite film morphology as exhamined by SEM imaging (Supporting Information, Figure S10-12) and photographs of the spin coated perovkite thin films (Supporting Information, Figure S13).
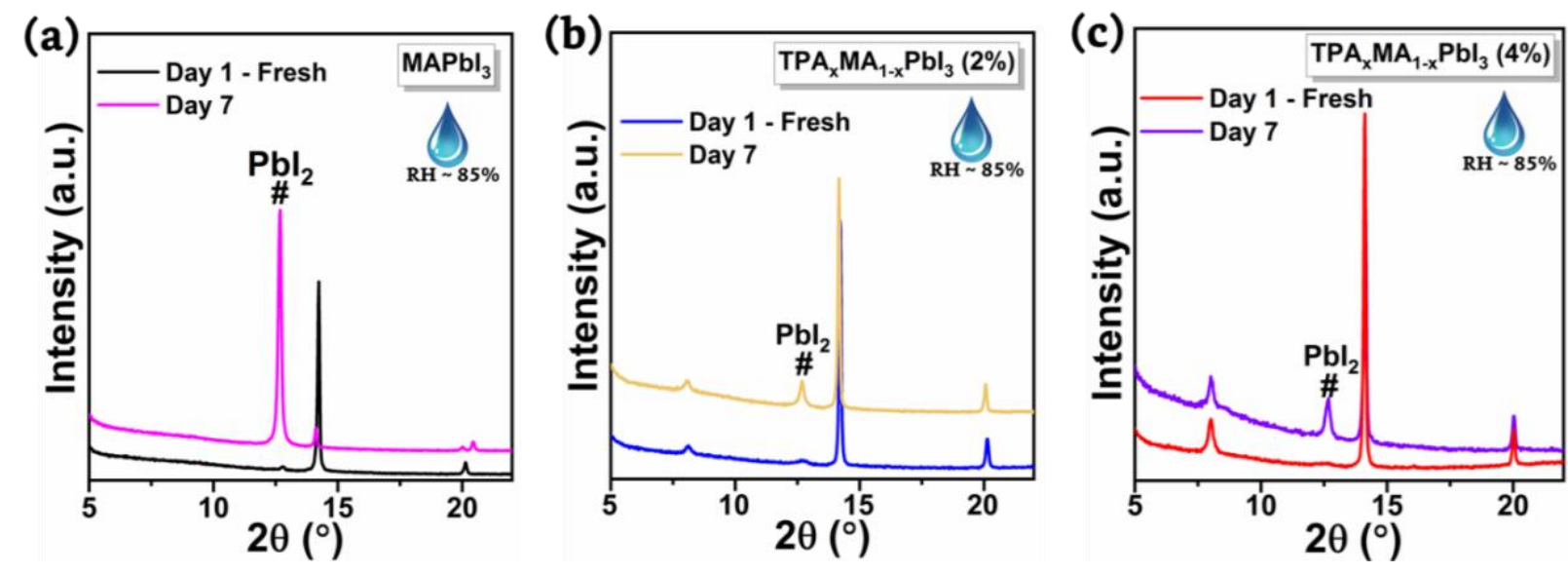

Figure 9. Stability of perovskite films: Comparison of X-ray diffractograms of the perovskite film before and after 7 days storage under $85 \%$ humidity chamber for (a) MAPI, (b) (TPA) $\times(\mathrm{MA})_{1-\mathrm{x}} \mathrm{PbI}_{3} 2 \%$, and (c) (TPA) $)_{\times}(\mathrm{MA})_{1-\mathrm{x}} \mathrm{PbI}_{3} 4 \%$. The films were spin-coated on FTO glass. 


\section{CONCLUSIONS}

To summarize, we report that the addition of low molar fractions of quaternary ammonium $\mathrm{TPA}^{+}$cation in $\mathrm{CH}_{3} \mathrm{NH}_{3} \mathrm{I}$ and $\mathrm{PbI}_{2}$ precursor solution leads to a mesostructured film consisting of smaller, better packed and defect passivated $\mathrm{CH}_{3} \mathrm{NH}_{3} \mathrm{PbI}_{3}$ nanocrystals. XRD and PL studies revealed that the mesostructured film consists of type-I heterostructure of MAPI in association with a lower-dimensional $\mathrm{TPAPb}_{4} \mathrm{I}_{9}$ intermediate phase forming likely at grain boundaries. The XRD results are complemented by $2 \mathrm{D}{ }^{1} \mathrm{H}$ solid-state NMR measurements, which showed nanoscale proximities between $\mathrm{TPA}^{+}$and $\mathrm{MA}^{+}$cations in $\mathrm{TPA}_{x} \mathrm{MA}_{1-\mathrm{x}} \mathrm{PbI}_{3} 4 \%$. As a result from the incorporation of $\mathrm{TPA}^{+}$, the film's homogeneity is significantly improved in both terms of photoluminescence yield and excited-state lifetime as demonstrated by FLIM imaging experiments. Devices based on TPA are exhibiting more than 17\% power conversion efficiency under A.M. 1.5G conditions, a value at a similar level of the controlled MAPI-devices. However, with respect to MAPI, $\mathrm{TPA}_{x} \mathrm{MA}_{1-\mathrm{xPbI}}$ exhibits a remarkable improvement in absorber stability regardless of the external ageing conditions (temperature, light, atmosphere). This work validates that specifically developed organic monovalent cation judiciously incorporated into 3D perovskite is a credible approach to improve perovskite solar cell performance and above all stability.

\section{METHODS}

Materials: Unless specified otherwise, all chemicals were purchased from Sigma-Aldrich. Mesoporous $\mathrm{TiO}_{2}$ paste, MAI and FK209 were purchased from Dyesol. $\mathrm{PbI}_{2}$ was purchased from Tokyo Chemical Industry Europe (TCI France). 
Device Fabrication: FTO glass substrate (NSG10) was cleaned with 2 vol $\%$ hellmanex solution in DI water, isopropanol (Sigma-Aldrich), acetone (Sigma- Aldrich) and treated with UV ozone cleaner for 15 min. To make a compact $\mathrm{TiO}_{2}$ blocking layer, the cleaned FTO glasses were coated with $0.15 \mathrm{M}$ titanium diisopropoxide bis(acetylacetonate) (75\% Aldrich) in 1-butanol (Aldrich) solution by spin-coating at $3000 \mathrm{rpm}$ for $30 \mathrm{~s}$ and was heated at $125^{\circ} \mathrm{C}$ for $5 \mathrm{~min}$. After the coated film was cooled down to room temperature, the same process was repeated with $0.3 \mathrm{M}$ titanium diisopropoxide bis(acetylacetonate) solution in 1-butanol. After this, the substrates were heated at $450{ }^{\circ} \mathrm{C}$ for $30 \mathrm{~min}$ to form a dense layer of $\mathrm{TiO}_{2}$. A $\sim 200 \mathrm{~nm}$ mesoporous $\mathrm{TiO}_{2}$ was coated on the substrate by spin coating at a speed of $4000 \mathrm{rpm}$ for $30 \mathrm{~s}$ with a ramp-up of 1000 $\mathrm{rpm} / \mathrm{s}$ from a commercially available $\mathrm{TiO}_{2}$ paste (Dyesol-30NRD) in ethanol. The weight ratio of $\mathrm{TiO}_{2}$ paste to ethanol is 6:1. After spin coating, the substrate was immediately dried on a hot plate at $100{ }^{\circ} \mathrm{C}$, and the substrates were then sintered at $500{ }^{\circ} \mathrm{C}$ for $30 \mathrm{~min}$ before the deposition of the perovskite layer. The precursor solution was prepared by dissolving 1 M MAI (159 mg) and 1.09 $\mathrm{M} \mathrm{PbI}_{2}(502.9 \mathrm{mg})$ in anhydrous $\mathrm{N}, \mathrm{N}$-dimethylformamide (0.8 mL, Sigma-Aldrich) and anhydrous dimethylsulfoxide ( $0.2 \mathrm{ml}$, Sigma-Aldrich). These solutions were then spin-coated on the substrate in a two-step procedure at $1000 \mathrm{rpm}$ for $10 \mathrm{~s}$ and $4000 \mathrm{rpm}$ for $20 \mathrm{~s}$, respectively. During the second step, $1 \mathrm{ml}$ of toluene was dropped $10 \mathrm{~s}$ before the end of the program. These spin-coated perovskite films were annealed at $110{ }^{\circ} \mathrm{C}$ for $30 \mathrm{~min}$ inside Ar-filled glovebox. The HTM was further deposited by spin coating at $3000 \mathrm{rpm}$ for $30 \mathrm{~s}$. The HTM solution was prepared by dissolving $91 \mathrm{mg}$ of Spiro-OMeTAD (Merck) with additives in $1 \mathrm{ml}$ of chlorobenzene. The additives were $21 \mu \mathrm{l}$ of Li-bis(trifluoromethanesulfonyl) imide from the stock solution (520 mg in $1 \mathrm{ml}$ of acetonitrile), $16 \mu \mathrm{l}$ of FK209 [tris(2-(1H-pyrazol-1-yl)-4-tertbutylpyridine)-cobalt(III) tris-(bis (trifluoromethylsulfonyl)imide] (375 $\mathrm{mg}$ in $1 \mathrm{ml}$ of 
acetonitrile) and $36 \mu \mathrm{l}$ of 4-tertbutylpyridine. The final step was the deposition of the $80 \mathrm{~nm}$ thick Au electrode at a rate of $\sim 0.3 \AA / \mathrm{s}$ by thermal evaporation using MBraun ProVap $4 \mathrm{G}$ evaporator. Characterization: The perovskite samples for characterization were prepared following exactly the same procedure as for the device fabrication. The XRD experiments were conducted on a Bruker AXS (D8 ADVANCE) diffractometer with $\mathrm{Cu} \mathrm{K \alpha}$ radiation $(\lambda=1.54 \AA)$. Scanning electron microscopy images were obtained using a FEI Quanta 200 FEG microscope. UV-Vis absorption spectra were recorded in a transmittance mode using a Cary5000 UV-Vis-NIR spectrometer. TCSPC experiments were carried out on Edinburgh Instrument FLS980 spectrometer using picosecond $475 \mathrm{~nm}$ laser diodes as an excitation source $(2 \mathrm{MHz})$ and a microchannel plate photomultiplier tube (MCP-PMT) Hamamatsu detector set after the first emission monochromator. The measurements were carried out in front-face. The typical instrument response function (IRF) value in this configuration was in the range from 80 to $90 \mathrm{ps.}$ The slit opening of excitation monochromator was $10 \mathrm{~nm}$ wide. The steady-state PL spectra were measured using same spectrometer with a continuous xenon arc lamp (450 W) for excitation in a double excitation / double emission monochromator setup to bring stray light rejection to less than $10^{-10}$. The slit width was $3 \mathrm{~nm}$. For this, the samples were excited at $450 \mathrm{~nm}$ and the emission was detected by a high-gain photomultiplier tube (PMT) detector mounted after the second emission monochromator. For both steady-state PL and TCSPC measurements, the perovskites were deposited on clean glass substrates and the samples were excited from front side, i.e. perovskite side. Fluorescence lifetime images were obtained using a homemade microscope. The excitation light was obtained using a picosecond laser from picoquant at 470 nm (laser head LDH-P-C-470 with a collimator and controlled by a pulse diode laser driver unit PDL 800-B). The excitation light was going through a beam expander to overfill the aperture of 
the objective and a bereck compensator (5540, New Focus) was also used to get a circular polarization. The excitation light was directed into an inverted Olympus IX81 and focused on the sample using a dichroic mirror (Semrock BrightLine R488) and an air objective (UplanSapo, $40 \times$, N.A. 0.95). The fluorescence was collected by the same objective lens, directed by the dichroic mirror, passed through the confocal pinhole $(100 \mu \mathrm{m})$, and filtered out by a long pass emission filter (Semrock BrightLine LP $496 \mathrm{~nm}$ ) before being directed to an avalanche photodiode-based single-photon counting modules (MPD, $50 \mathrm{~mm}$, Grade D, < $50 \mathrm{cps}$ and IRF of 50 ps). The sample was mounted on a three-dimensional translation stage (E-725, Physik Instrument) which allows scanning pixel-by-pixel an entire area on the sample of $24 \times 24 \mu \mathrm{m}(8$ $\mu \mathrm{m}$ variation in z-axis) and controlled by Symphotime (Picoquant). Photon arrival time for each pixels was obtained using a Picoharp300 and calculation of average lifetime for each pixel was done by Symphotime. Pixel dwell time was fixed to $5 \mathrm{~ms}$ to avoid any photo-degradation of the film during acquisition. For average lifetime, images (128 x 128 pixels) were rebinned by 4 to get enough photon statics and only pixels that have more than 500 counts/s were fitted. An average lifetime in intensity was calculated from a reconvoluted fit of IRF (scatter of laser) and a sum of 4 exponential decays. Note that for FLIM experiments, the laser fluence is about 10 times higher than sun irradiation which leads to an increase of bimolecular recombination and give a multiexponential decay.

The powdered TPAI precursor and th scratched-off thin films of $\mathrm{TPA}_{\mathrm{x}} \mathrm{MA}_{1-\mathrm{x}} \mathrm{PbI}_{3} 4 \%$ obtained from 15 spin-coated substrates were separately packed into $1.3 \mathrm{~mm}$ (outer diameter) rotors fitted close with Vespel $^{\circledR}$ caps. All 1D and 2D ${ }^{1} \mathrm{H}$ NMR experiments were carried out at room temperature on a $18.8 \mathrm{~T}$ Bruker AVANCE NEO spectrometer equipped with $1.3 \mathrm{~mm}$ doubleresonance H/X MAS probe. The sample was spun at a frequency of $35 \mathrm{kHz}$, except in Figure $3 \mathrm{~b}$. 
Single-pulse ${ }^{1} \mathrm{H}$ MAS NMR experiments are carried out by co-adding 512 transients with a relaxation delay of $2 \mathrm{~s}$, corresponding to a total experimental time of 18 minutes each. The 2D ${ }^{1} \mathrm{H}-{ }^{1} \mathrm{H}$ spin-diffusion (SD) spectra were acquired using $400 t_{1}$ increments, each by co-adding 16 transients, using the States method to achieve sign discrimination in $F_{1}$ dimension with a rotorsynchronized $t_{1}$ increment of $16.6 \mu \mathrm{s}$. The $2 \mathrm{D}{ }^{1} \mathrm{H}-{ }^{1} \mathrm{H}$ SD spectra were acquired using $1 \mathrm{~ms}, 10$ $\mathrm{ms}, 100 \mathrm{~ms}$ and $500 \mathrm{~ms}$ of mixing times, each corresponding to an experimental time of $3.5 \mathrm{~h}$ using a relaxation delay of $2 \mathrm{~s}$. The $2 \mathrm{D}{ }^{1} \mathrm{H}-{ }^{1} \mathrm{H}$ double-quantum (DQ) single-quantum (SQ) spectra were acquired using one rotor period Back-to-Back sequence. [Cite: Feike, M. et al J. Magn. Reson. 1996, 122A, 214-221; Saalwächter, K.et al., Journal of Magnetic Resonance 2011, 212 (1), 204-215] The DQ coherences were excited and reconverted using a16-step phase cycle. 2D ${ }^{1} \mathrm{H}-{ }^{1} \mathrm{H}$ DQ-SQ spectra were acquired using $128 t_{1}$ increments, each by co-adding 16 transients, using the States method to achieve sign discrimination in $F_{1}$ dimension with a rotorsynchronized $t_{1}$ increment of $16.6 \mu \mathrm{s}$, corresponding to an overall experimental time of $2.5 \mathrm{~h}$ using a $2 \mathrm{~s}$ recycle delay. The ${ }^{1} \mathrm{H}$ chemical shifts are calibrated with respect to neat TMS using adamantane as an external reference $\left({ }^{1} \mathrm{H}\right.$ resonance, $\left.1.85 \mathrm{ppm}\right)$.

Current density-voltage (J-V) characteristics of PSCs were recorded by means of a Keithley computer-controlled digital sourcemeter (2412A) combined with a 3A class Newport SOL3A sun simulator with an A.M. $1.5 \mathrm{G}$ filter $\left(100 \mathrm{mWcm}^{-2}\right)$. The light intensity was calibrated with an NREL-certified KG5-filtered Si reference diode. The solar cells were masked (3D printed mask) with an aperture of $0.09 \mathrm{~cm}^{2}$ to define the active area. UPS measurements were performed using a helium discharge lamp in an Escalab 250Xi spectrometer from Thermo. UPS spectra were recorded with the following parameters: $\mathrm{HeI}$ at $21.22 \mathrm{eV}$, sample bias $-10 \mathrm{~V}$ and pass energy of $2 \mathrm{eV}$. The binding energy for UPS was calibrated using the Fermi edge of sputtered cleaned gold 
substrate. UPS measurements are very sensitive to the surface (probing depth $\sim 2 \mathrm{~nm}$ ). Since the preparation of the samples was not performed in situ, their exposition to air induces adventitious carbon adsorption on their surface which prevents correct UPS analysis. In order to remove this contamination, we use an Ar cluster gun ( $8 \mathrm{kV}, 2000$ atoms) to gently clean the surface inside the spectrometer prior to UPS analysis. These large Ar clusters are able to remove organic contamination without destroying the perovskite structure.

Stability testing: In this work, we did three kinds of stability tests carried out under open-circuit conditions. The first set of stability test was done in an argon atmosphere. The devices were stored in an argon-filled glovebox and were taken periodically for I-V measurements that were done in ambient condition. For the second set of stability test, the devices were stored in ambient air and light with a relative humidity of $55 \pm 5 \%$ and temperature of $20 \pm 5{ }^{\circ} \mathrm{C}$. The third test to check thermal stability was done at $60{ }^{\circ} \mathrm{C}$ in an argon atmosphere. Devices were put on a ceramic hot plate at $60{ }^{\circ} \mathrm{C}$ in the argon-filled glovebox and were taken out every $72 \mathrm{~h}$ for I-V measurements, which was done in ambient conditions. For stability testing for perovskites films, the films were stored for a week in an in-house-built humidity chamber with $\sim 85 \%$ relative humidity.

\section{ASSOCIATED CONTENT}

The Supporting Information is available free of charge on the ACS Publications website The following files are available free of charge. Figure S1. XRD pattern of the resulting film spin-coated on glass with 1:1, 1:2 and 1:4 ratio between TPAI and PbI. Figure S2. X-ray Diffraction pattern of TPAI film obtained by spin-coating on the glass. Figure S3. UV-visible absorption spectrum and corresponding Tauc-plot for (TPA) $\mathrm{Pb}_{4} \mathrm{I}_{9}$ film spin-coated on glass. Figure S4. Photoluminescence mapping of $\mathrm{MAPbI}_{3}, \mathrm{TPA}_{x} \mathrm{MA}_{1-x} \mathrm{PbI}_{3}(2 \%)$ and $\mathrm{TPA}_{x} \mathrm{MA}_{1-x} \mathrm{PbI}_{3}$ (4\%). Figure S5. The PL lifetime histogram of the samples extracted from FLIM images. Figure S6. UV-visible absorption spectrum measured in transmittance for fresh $\mathrm{MAPbI}_{3}$ film and after 7 
days storage at room temperature under $85 \%$ humidity level. The films were spin-coated upon FTO glass. Figure S7. UV-visible absorption spectrum measured in transmittance for fresh $\mathrm{TPA}_{\mathrm{x}} \mathrm{MA}_{1-\mathrm{x}} \mathrm{PbI}_{3}(2 \%)$ film and after 7 days storage at room temperature under $85 \%$ humidity

level. The films were spin-coated upon FTO glass. Figure S8. UV-visible absorption spectrum measured in transmittance for fresh $\mathrm{TPA}_{x} \mathrm{MA}_{1-\mathrm{x}} \mathrm{PbI}_{3}(4 \%)$ film and after 7 days storage at room temperature under $85 \%$ humidity level. The films were spin-coated upon FTO glass. Figure S9. SEM image of the fresh $\mathrm{MAPbI}_{3}$ film and after 7 days storage at room temperature under $85 \%$ humidity level. Figure S10. SEM image of the fresh $\mathrm{TPA}_{x} \mathrm{MA}_{1-\mathrm{x}} \mathrm{PbI}_{3}(2 \%)$ film and after 7 days storage at room temperature under $85 \%$ humidity level. Figure S11. SEM image of the fresh $\mathrm{TPA}_{x} \mathrm{MA}_{1-\mathrm{x}} \mathrm{PbI}_{3}(4 \%)$ film and after 7 days storage at room temperature under $85 \%$ humidity level. Figure S12. Photograph showing comparison of $\mathrm{MAPbI}_{3}, \mathrm{TPA}_{x} \mathrm{MA}_{1-x} \mathrm{PbI}_{3}(2 \%)$ and $\mathrm{TPA}_{x} \mathrm{MA}_{1-\mathrm{x}} \mathrm{PbI}_{3}$ (4\%) films stored at room temperature under $85 \%$ relative humidity level for 7 days. The films were spin-coated on FTO glass.

\section{AUTHOR INFORMATION}

\section{Corresponding Author}

Email: frederic.sauvage@u-picardie.fr (F.S)

\section{Present Addresses}

Anurag Krishna (A.K.) is presently at Laboratory of Photomolecular Science, Ecole Polytechnique Fédérale de Lausanne, 1015 Lausanne, Switzerland

\section{Author Contributions}

A.K. assembled devices, optimized performances and carried out stability testing in association with M.A.A.K. G. N. M. R. carried out solid-state NMR experiments. A.K. and F.S. carried out PL and TCPSC experiments. M.T.D. and M.S. performed FLIM experiments. A.F. performed 
UPS analysis. All authors have contributed to the scientific discussion. A.K. and F.S. have prepared and finalized the manuscript.

\section{Notes}

The authors declare no competing financial interest

\section{ACKNOWLEDGMENT}

F.S. wish to thank H2020 research and innovation program for IMPRESSIVE project under grant agreement $\mathrm{n}^{\circ} 826013$ and region Hauts-de-France, FEDER and EDF for PhD grants of M.A. and A.K. M.S. is indebted to the Chevreul Institute (FR 2638) and the Agence National de la Recherche (ANR-14-CE08-0015-01 Ultrafast Nanoscopy) for financial support. Chevreul Institute (FR 2638), Ministère de l'Enseignement Supérieur, de la Recherche et de l'Innovation, Hauts-de-France Region and FEDER are acknowledged for supporting and funding partially this work. G.N.M.R, L.D and O.L. gratefully acknowledge the financial support from the IR-RMNTHC FR-3050 CNRS France for conducting solid-state NMR measurements.

\section{REFERENCES}

(1) Lee, M. M.; Teuscher, J.; Miyasaka, T.; Murakami, T. N.; Snaith, H. J. Efficient Hybrid Solar Cells Based on Meso-Superstructured Organometal Halide Perovskites. Science (80.). 2012.

(2) Kim, H. S.; Lee, C. R.; Im, J. H.; Lee, K. B.; Moehl, T.; Marchioro, A.; Moon, S. J.; Humphry-Baker, R.; Yum, J. H.; Moser, J. E.; et al. Lead Iodide Perovskite Sensitized All-Solid-State Submicron Thin Film Mesoscopic Solar Cell with Efficiency Exceeding 9\%. Sci. Rep. 2012, 2, 1-7. 
(3) Xing, G.; Mathews, N.; Sun, S.; Lim, S. S.; Lam, Y. M.; Gräzel, M.; Mhaisalkar, S.;

Sum, T. C. Long-Range Balanced Electron-and Hole-Transport Lengths in OrganicInorganic $\mathrm{CH}_{3} \mathrm{NH}_{3} \mathrm{PbI}_{3}$. Science (80-. ). 2013, 342 (6156), 344-347.

(4) Saparov, B.; Mitzi, D. B. Organic-Inorganic Perovskites: Structural Versatility for Functional Materials Design. Chemical Reviews. 2016, 4558-4596.

(5) Jeon, N. J.; Noh, J. H.; Yang, W. S.; Kim, Y. C.; Ryu, S.; Seo, J.; Seok, S. Il. Compositional Engineering of Perovskite Materials for High-Performance Solar Cells. Nature 2015, 517 (7535), 476-480.

(6) NREL Efficiency Chart https://www.nrel.gov/pv/assets/images/efficiency-chart.png.

(7) Snaith, H. J. Present Status and Future Prospects of Perovskite Photovoltaics. Nat. Mater. 2018, $17(5), 372-376$.

(8) Manser, J. S.; Saidaminov, M. I.; Christians, J. A.; Bakr, O. M.; Kamat, P. V. Making and Breaking of Lead Halide Perovskites. Acc. Chem. Res. 2016, 49 (2), 330-338.

(9) Niu, G.; Guo, X.; Wang, L. Review of Recent Progress in Chemical Stability of Perovskite Solar Cells. J. Mater. Chem. A 2015, 3 (17), 8970-8980.

(10) Slavney, A. H.; Smaha, R. W.; Smith, I. C.; Jaffe, A.; Umeyama, D.; Karunadasa, H. I. Chemical Approaches to Addressing the Instability and Toxicity of Lead-Halide Perovskite Absorbers. Inorg. Chem., 2017, 46-55.

(11) Conings, B.; Drijkoningen, J.; Gauquelin, N.; Babayigit, A.; D’Haen, J.; D’Olieslaeger, L.; Ethirajan, A.; Verbeeck, J.; Manca, J.; Mosconi, E.; et al. Intrinsic Thermal Instability of Methylammonium Lead Trihalide Perovskite. Adv. Energy Mater. 2015, 5 (15), 1-8.

(12) Saliba, M.; Matsui, T.; Seo, J. Y.; Domanski, K.; Correa-Baena, J. P.; Nazeeruddin, M. K.; Zakeeruddin, S. M.; Tress, W.; Abate, A.; Hagfeldt, A.; et al. Cesium-Containing 
Triple Cation Perovskite Solar Cells: Improved Stability, Reproducibility and High Efficiency. Energy Environ. Sci. 2016, 9 (6), 1989-1997.

(13) Correa-Baena, J.-P.; Saliba, M.; Buonassisi, T.; Grätzel, M.; Abate, A.; Tress, W.; Hagfeldt, A. Promises and Challenges of Perovskite Solar Cells. Science (80-. ). 2017, 358 (6364), $739-744$.

(14) Zheng, X.; Chen, B.; Dai, J.; Fang, Y.; Bai, Y.; Lin, Y.; Wei, H.; Zeng, X. C.; Huang, J. Defect Passivation in Hybrid Perovskite Solar Cells Using Quaternary Ammonium Halide Anions and Cations. Nat. Energy 2017, 2 (7), 17102.

(15) Wang, Q.; Chen, B.; Liu, Y.; Deng, Y.; Bai, Y.; Dong, Q.; Huang, J. Scaling Behavior of Moisture-Induced Grain Degradation in Polycrystalline Hybrid Perovskite Thin Films. Energy Environ. Sci. 2017, 10 (2), 516-522.

(16) Yang, B.; Dyck, O.; Poplawsky, J.; Keum, J.; Puretzky, A.; Das, S.; Ivanov, I.; Rouleau, C.; Duscher, G.; Geohegan, D.; et al. Perovskite Solar Cells with Near 100\% Internal Quantum Efficiency Based on Large Single Crystalline Grains and Vertical Bulk Heterojunctions. J. Am. Chem. Soc. 2015, 137 (29), 9210-9213.

(17) Krishna, A.; Gottis, S.; Nazeeruddin, M. K.; Sauvage, F. Mixed Dimensional 2D/3D Hybrid Perovskite Absorbers: The Future of Perovskite Solar Cells? Adv. Funct. Mater. 2019, $29(8), 1806482$.

(18) Chen, Y.; Sun, Y.; Peng, J.; Tang, J.; Zheng, K.; Liang, Z. 2D Ruddlesden-Popper Perovskites for Optoelectronics. Advanced Materials. 2017, 1-15.

(19) Slavney, A. H.; Smaha, R. W.; Smith, I. C.; Jaffe, A.; Umeyama, D.; Karunadasa, H. I. Chemical Approaches to Addressing the Instability and Toxicity of Lead-Halide Perovskite Absorbers. Inorg. Chem. 2017, 56 (1), 46-55. 
(20) Smith, I. C.; Hoke, E. T.; Solis-Ibarra, D.; McGehee, M. D.; Karunadasa, H. I. A Layered Hybrid Perovskite Solar-cell Absorber with Enhanced Moisture Stability. Angew. Chemie 2014, $126(42), 11414-11417$.

(21) Cao, D. H.; Stoumpos, C. C.; Farha, O. K.; Hupp, J. T.; Kanatzidis, M. G. 2D Homologous Perovskites as Light-Absorbing Materials for Solar Cell Applications. J. Am. Chem. Soc. 2015, 137 (24), 7843-7850.

(22) Ma, C.; Shen, D.; Ng, T. W.; Lo, M. F.; Lee, C. S. 2D Perovskites with Short Interlayer Distance for High-Performance Solar Cell Application. Adv. Mater. 2018, 30 (22), 2-7.

(23) Tsai, H.; Nie, W.; Blancon, J.-C.; Stoumpos, C. C.; Asadpour, R.; Harutyunyan, B.; Neukirch, A. J.; Verduzco, R.; Crochet, J. J.; Tretiak, S.; et al. High-Efficiency TwoDimensional Ruddlesden-Popper Perovskite Solar Cells. Nature 2016, 536 (7616), 312316.

(24) Koh, T. M.; Shanmugam, V.; Schlipf, J.; Oesinghaus, L.; Müller-Buschbaum, P.; Ramakrishnan, N.; Swamy, V.; Mathews, N.; Boix, P. P.; Mhaisalkar, S. G. Nanostructuring Mixed-Dimensional Perovskites: A Route Toward Tunable, Efficient Photovoltaics. Adv. Mater. 2016, 28 (19), 3653-3661.

(25) Ye, T.; Bruno, A.; Han, G.; Koh, T. M.; Li, J.; Jamaludin, N. F.; Soci, C.; Mhaisalkar, S. G.; Leong, W. L. Efficient and Ambient-Air-Stable Solar Cell with Highly Oriented 2D@3D Perovskites. Adv. Funct. Mater. 2018, 1801654, 1-8.

(26) Cho, Y.; Soufiani, A. M.; Yun, J. S.; Kim, J.; Lee, D. S.; Seidel, J.; Deng, X.; Green, M. A.; Huang, S.; Ho-Baillie, A. W. Y. Mixed 3D-2D Passivation Treatment for MixedCation Lead Mixed-Halide Perovskite Solar Cells for Higher Efficiency and Better Stability. Adv. Energy Mater. 2018, 8 (20), 1-10 
(27) Poli, I.; Eslava, S.; Cameron, P. Tetrabutylammonium Cations for Moisture-Resistant and Semitransparent Perovskite Solar Cells. J. Mater. Chem. A 2017, 00, 1-9.

(28) Grancini, G.; Roldán-Carmona, C.; Zimmermann, I.; Mosconi, E.; Lee, X.; Martineau, D.; Narbey, S.; Oswald, F.; De Angelis, F.; Graetzel, M.; et al. One-Year Stable Perovskite Solar Cells by 2D/3D Interface Engineering. Nat. Commun. 2017, 8, 1-8.

(29) Wang, Z.; Lin, Q.; Chmiel, F. P.; Sakai, N.; Herz, L. M.; Snaith, H. J. Efficient AmbientAir-Stable Solar Cells with 2D-3D Heterostructured Butylammonium-CaesiumFormamidinium Lead Halide Perovskites. Nat. Energy 2017, 2 (9), 1-10.

(30) Naphade, R.; Zhao, B.; Richter, J. M.; Booker, E.; Krishnamurthy, S.; Friend, R. H.; Sadhanala, A.; Ogale, S. High Quality Hybrid Perovskite Semiconductor Thin Films with Remarkably Enhanced Luminescence and Defect Suppression via Quaternary Alkyl Ammonium Salt Based Treatment. Adv. Mater. Interfaces 2017, 4 (19), 1-8.

(31) Shih, Y. C.; Lan, Y. B.; Li, C. S.; Hsieh, H. C.; Wang, L.; Wu, C. I.; Lin, K. F. AminoAcid-Induced Preferential Orientation of Perovskite Crystals for Enhancing Interfacial Charge Transfer and Photovoltaic Performance. Small 2017, 13 (22), 1-10.

(32) Docampo, P.; Hanusch, F. C.; Giesbrecht, N.; Angloher, P.; Ivanova, A.; Bein, T. Influence of the Orientation of Methylammonium Lead Iodide Perovskite Crystals on Solar Cell Performance. APL Mater. 2014, 2 (8).

(33) Chen, A. Z.; Foley, B. J.; Ma, J. H.; Alpert, M. R.; Niezgoda, J. S.; Choi, J. J. Crystallographic Orientation Propagation in Metal Halide Perovskite Thin Films. J. Mater. Chem. A 2017, 5 (17), 7796-7800.

(34) Jacobsson, T. J.; Correa-Baena, J. P.; Halvani Anaraki, E.; Philippe, B.; Stranks, S. D.; Bouduban, M. E. F.; Tress, W.; Schenk, K.; Teuscher, J.; Moser, J. E.; et al. Unreacted 
$\mathrm{PbI}_{2}$ as a Double-Edged Sword for Enhancing the Performance of Perovskite Solar Cells. J. Am. Chem. Soc. 2016, 138 (32), 10331-10343.

(35) Kieslich, G.; Sun, S.; Cheetham, A. K. Solid-State Principles Applied to OrganicInorganic Perovskites: New Tricks for an Old Dog. Chem. Sci. 2014, 5 (12), 4712-4715.

(36) Li, W.; Wang, Z.; Deschler, F.; Gao, S.; Friend, R. H.; Cheetham, A. K. Chemically Diverse and Multifunctional Hybrid Organic-Inorganic Perovskites. Nat. Rev. Mater. 2017, 2 (3).

(37) Nilsson, E. J.; Alfredsson, V.; Bowron, D. T.; Edler, K. J. A Neutron Scattering and Modelling Study of Aqueous Solutions of Tetramethylammonium and Tetrapropylammonium Bromide. Phys. Chem. Chem. Phys. 2016, 18 (16), 11193-11201.

(38) De Wolf, S.; Holovsky, J.; Moon, S. J.; Löper, P.; Niesen, B.; Ledinsky, M.; Haug, F. J.; Yum, J. H.; Ballif, C. Organometallic Halide Perovskites: Sharp Optical Absorption Edge and Its Relation to Photovoltaic Performance. J. Phys. Chem. Lett. 2014, 5 (6), 10351039.

(39) Lee, J. W.; Bae, S. H.; Hsieh, Y. T.; De Marco, N.; Wang, M.; Sun, P.; Yang, Y. A Bifunctional Lewis Base Additive for Microscopic Homogeneity in Perovskite Solar Cells. Chem 2017, 3 (2), 290-302.

(40) Emara, J.; Schnier, T.; Pourdavoud, N.; Riedl, T.; Meerholz, K.; Olthof, S. Impact of Film Stoichiometry on the Ionization Energy and Electronic Structure of $\mathrm{CH}_{3} \mathrm{NH}_{3} \mathrm{PbI}_{3}$ Perovskites. Adv. Mater. 2016, 28 (3), 553-559.

(41) Wang, R.; Zhuo, M. P.; Li, J.; Zhai, T.; Yang, J.; Fu, K.; Liao, L. S.; Liu, L.; Duhm, S. Surface $\mathrm{CH}_{3} \mathrm{NH}_{3}{ }^{+}$to $\mathrm{CH}_{3}{ }^{+}$Ratio Impacts the Work Function of Solution-Processed and Vacuum-Sublimed $\mathrm{CH}_{3} \mathrm{NH}_{3} \mathrm{PbI}_{3}$ Thin Films. Adv. Mater. Interfaces 2019, 6 (6), 1-8. 
(42) Yin, W. J.; Shi, T.; Yan, Y. Unusual Defect Physics in CH3NH3PbI3 Perovskite Solar Cell Absorber. Appl. Phys. Lett. 2014, 104 (6).

Zu, F.; Amsalem, P.; Egger, D. A.; Wang, R.; Wolff, C. M.; Fang, H.; Loi, M. A.; Neher, D.; Kronik, L.; Duhm, S.; et al. Constructing the Electronic Structure of CH 3 NH 3 PbI 3 and $\mathrm{CH} 3 \mathrm{NH} 3 \mathrm{PbBr} 3$ Perovskite Thin Films from Single-Crystal Band Structure Measurements. J. Phys. Chem. Lett. 2019, 10 (3), 601-609.

(44) Endres, J.; Egger, D. A.; Kulbak, M.; Kerner, R. A.; Zhao, L.; Silver, S. H.; Hodes, G.; Rand, B. P.; Cahen, D.; Kronik, L.; et al. Valence and Conduction Band Densities of States of Metal Halide Perovskites: A Combined Experimental-Theoretical Study. J. Phys. Chem. Lett. 2016, 7 (14), 2722-2729.

(45) Son, D. Y.; Lee, J. W.; Choi, Y. J.; Jang, I. H.; Lee, S.; Yoo, P. J.; Shin, H.; Ahn, N.; Choi, M.; Kim, D.; et al. Self-Formed Grain Boundary Healing Layer for Highly Efficient $\mathrm{CH}_{3} \mathrm{NH}_{3} \mathrm{PbI}_{3}$ Perovskite Solar Cells. Nat. Energy 2016, 1 (7), 1-8.

(46) Dong; Shi; Valerio; Adinolfi; Riccardo; Comin; Mingjian; Yuan; Erkki; Alarousu; et al. Low Trap-State Density and Long Carrier Diffusion in Organolead Trihalide Perovskite Single Crystals. Science (80-. ). 2015, 347 (6221), 519-522.

(47) de Quilettes, D. W.; Vorpahl, S. M.; Stranks, S. D.; Nagaoka, H.; Eperon, G. E.; Ziffer, M. E.; Snaith, H. J.; Ginger, D. S. Impact of Microstructure on Local Carrier Lifetime in Perovskite Solar Cells. Science (80-. ). 2015, 348 (6235), 683-686.

(48) Dequilettes, D. W.; Koch, S.; Burke, S.; Paranji, R. K.; Shropshire, A. J.; Ziffer, M. E.; Ginger, D. S. Photoluminescence Lifetimes Exceeding $8 \mathrm{Ms}$ and Quantum Yields Exceeding 30\% in Hybrid Perovskite Thin Films by Ligand Passivation. ACS Energy Lett. 2016, 1 (2), 438-444. 
(49) Merdasa, A.; Kiligaridis, A.; Rehermann, C.; Abdi-Jalebi, M.; Stöber, J.; Louis, B.; Gerhard, M.; Stranks, S.D.; Unger, E.L.; Scheblykin, I.G. Impact of Excess Lead Iodide on the Recombination Kinetics in Metal Halide Perovskites. ACS Energy Lett. 2019, 4, $1370-1378$.

(50) Agrawal, A.; Dar, T. A.; Phase, D. M.; Sen, P. Type I and Type II Band Alignments in ZnO/MgZnO Bilayer Films. Appl. Phys. Lett. 2014, 105 (8), 81603.

(51) Liu, B.; Long, M.; Cai, M.; Ding, L.; Yang, J. Interfacial Charge Behavior Modulation in 2D/3D Perovskite Heterostructure for Potential High-Performance Solar Cells. Nano Energy 2019, 59, 715-720.

(52) Braly, I. L.; deQuilettes, D. W.; Pazos-Outón, L. M.; Burke, S.; Ziffer, M. E.; Ginger, D. S.; Hillhouse, H. W. Hybrid Perovskite Films Approaching the Radiative Limit with over 90\% Photoluminescence Quantum Efficiency. Nat. Photonics 2018, 12 (6), 355-361.

(53) Domanski, K.; Alharbi, E. A.; Hagfeldt, A.; Grätzel, M.; Tress, W. Systematic Investigation of the Impact of Operation Conditions on the Degradation Behaviour of Perovskite Solar Cells. Nat. Energy 2018, 3 (1), 61-67.

(54) Wang, R.; Xue, J.; Meng, L.; Lee, J.-W.; Zhao, Z.; Sun, P.; Cai, L.; Huang, T.; Wang, Z.; Wang, Z.-K.; et al. Caffeine Improves the Performance and Thermal Stability of Perovskite Solar Cells. Joule 2019, 1-14.

(55) Wang, R.; Mujahid, M.; Duan, Y.; Wang, Z.-K.; Xue, J.; Yang, Y. A Review of Perovskites Solar Cell Stability. Adv. Funct. Mater. 2019, 0 (0), 1808843.

(56) Krishna, A.; Grimsdale, A. C. Hole Transporting Materials for Mesoscopic Perovskite Solar Cells - towards a Rational Design? J. Mater. Chem. A 2017, 5 (32), 16446-16466. 


\section{Defect passivation and stability enhancement in lead halide perovskite via incorporation of tetrapropylammonium cation}

Anurag Krishna ${ }^{\dagger}$, Mohammad Ali Akhavan Kazemi ${ }^{\dagger}$, Mai Trang Do ${ }^{\ddagger}$, Michel Sliwa ${ }^{\ddagger}$, G. N. Manjunatha Reddy ${ }^{\S}$, Laurent Delevoye ${ }^{\S}$, Olivier Lafon ${ }^{\S}$, Alexandre Felten ${ }^{\#}$, Sébastien Gottis ${ }^{\dagger}$, and Frédéric Sauvage ${ }^{\dagger *}$

Keywords: Stable Perovskites, Defect Passivation, 2D perovskites, molecular engineering

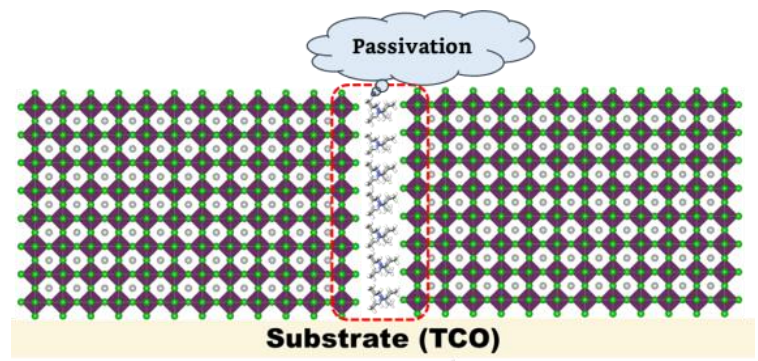

Stable perovskite thin films and solar cells are obtained by judicious incorporation of multifunctional tetrapropylammonium (TPA) cations in methylammonium iodide $\left(\mathrm{MAPbI}_{3}\right)$. Upon addition of TPA, a heterostructure is formed which leads to passivation of defects along with improved morphology.

This study highlights a new strategy to enhance the stability of PSCs while maintaining high performance. 